Supporting Information for

\title{
Calosides A-F, Cardenolides from Calotropis gigantea and Their Cytotoxic Activity
}

Mai T. T. Nguyen,,$+\underset{\dagger}{\dagger}$ Khang D. H. Nguyen, ${ }^{\dagger}$ Phu H. Dang, ${ }^{\dagger}$ Hai X. Nguyen,${ }^{\dagger}$ Suresh Awale,,${ }^{*} \S$ and Nhan T. Nguyen, $*, \dagger,+$

$\dagger$ Faculty of Chemistry and ${ }^{\ddagger}$ Cancer Research Laboratory, VNUHCM-University of Science, 227 Nguyen Van Cu Street, District 5, Ho Chi Minh City, Vietnam

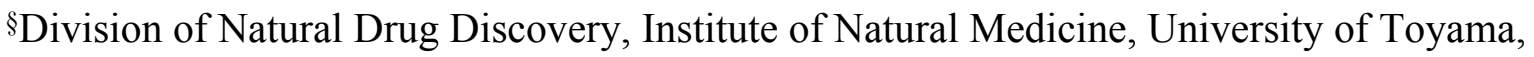
2630 Sugitani, Toyama 930-0194, Japan 


\section{List of Figures.}

Figure S1. ${ }^{1} \mathrm{H}$ NMR spectrum of compound 1 (500 MHz, DMSO- $d_{6}$ )

Figure S2. ${ }^{13} \mathrm{C}$ NMR spectrum of compound 1 (125 MHz, DMSO- $\left.d_{6}\right)$

Figure S3. HSQC NMR spectrum of compound 1

Figure S4. HMBC NMR spectrum of compound 1

Figure S5. NOESY NMR spectrum of compound 1

Figure S6. HR-ESIMS of compound 1

Figure S7. ${ }^{1} \mathrm{H}$ NMR spectrum of compound $2\left(500 \mathrm{MHz}\right.$, acetone- $\left.d_{6}\right)$

Figure S8. ${ }^{13} \mathrm{C}$ NMR spectrum of compound 2 (125 MHz, acetone- $d_{6}$ )

Figure S9. HSQC NMR spectrum of compound 2

Figure S10. HMBC NMR spectrum of compound 2

Figure S11. NOESY NMR spectrum of compound 2

Figure S12. HR-ESIMS of compound 2

Figure S13. ${ }^{1} \mathrm{H}$ NMR spectrum of compound 3 (500 MHz, DMSO- $d_{6}$ )

Figure S14. ${ }^{13} \mathrm{C}$ NMR spectrum of compound $3\left(125 \mathrm{MHz}, \mathrm{DMSO}-d_{6}\right)$

Figure S15. HSQC NMR spectrum of compound 3

Figure S16. HMBC NMR spectrum of compound 3

Figure S17. NOESY NMR spectrum of compound 3

Figure S18. HR-ESIMS of compound 3

Figure S19. ${ }^{1} \mathrm{H}$ NMR spectrum of compound 4 (500 MHz, DMSO- $d_{6}$ )

Figure S20. ${ }^{13} \mathrm{C}$ NMR spectrum of compound 4 (125 MHz, DMSO- $\left.d_{6}\right)$

Figure S21. HSQC NMR spectrum of compound 4

Figure S22. HMBC NMR spectrum of compound 4 
Figure S23. NOESY NMR spectrum of compound 4

Figure S24. HR-ESIMS of compound 4

Figure S25. ${ }^{1} \mathrm{H}$ NMR spectrum of compound 5 (500 MHz, DMSO- $d_{6}$ )

Figure S26. ${ }^{13} \mathrm{C}$ NMR spectrum of compound 5 (125 MHz, DMSO- $d_{6}$ )

Figure S27. HSQC NMR spectrum of compound 5

Figure S28. HMBC NMR spectrum of compound $\mathbf{5}$

Figure S29. NOESY NMR spectrum of compound $\mathbf{5}$

Figure S30. HR-ESIMS of compound 5

Figure S31. ${ }^{1} \mathrm{H}$ NMR spectrum of compound 6 (500 MHz, DMSO- $d_{6}$ )

Figure S32. ${ }^{13} \mathrm{C}$ NMR spectrum of compound $6\left(125 \mathrm{MHz}, \mathrm{DMSO}-d_{6}\right)$

Figure S33. HSQC NMR spectrum of compound 6

Figure S34. HMBC NMR spectrum of compound 6

Figure S35. NOESY NMR spectrum of compound 6

Figure S36. HR-ESIMS of compound 6 


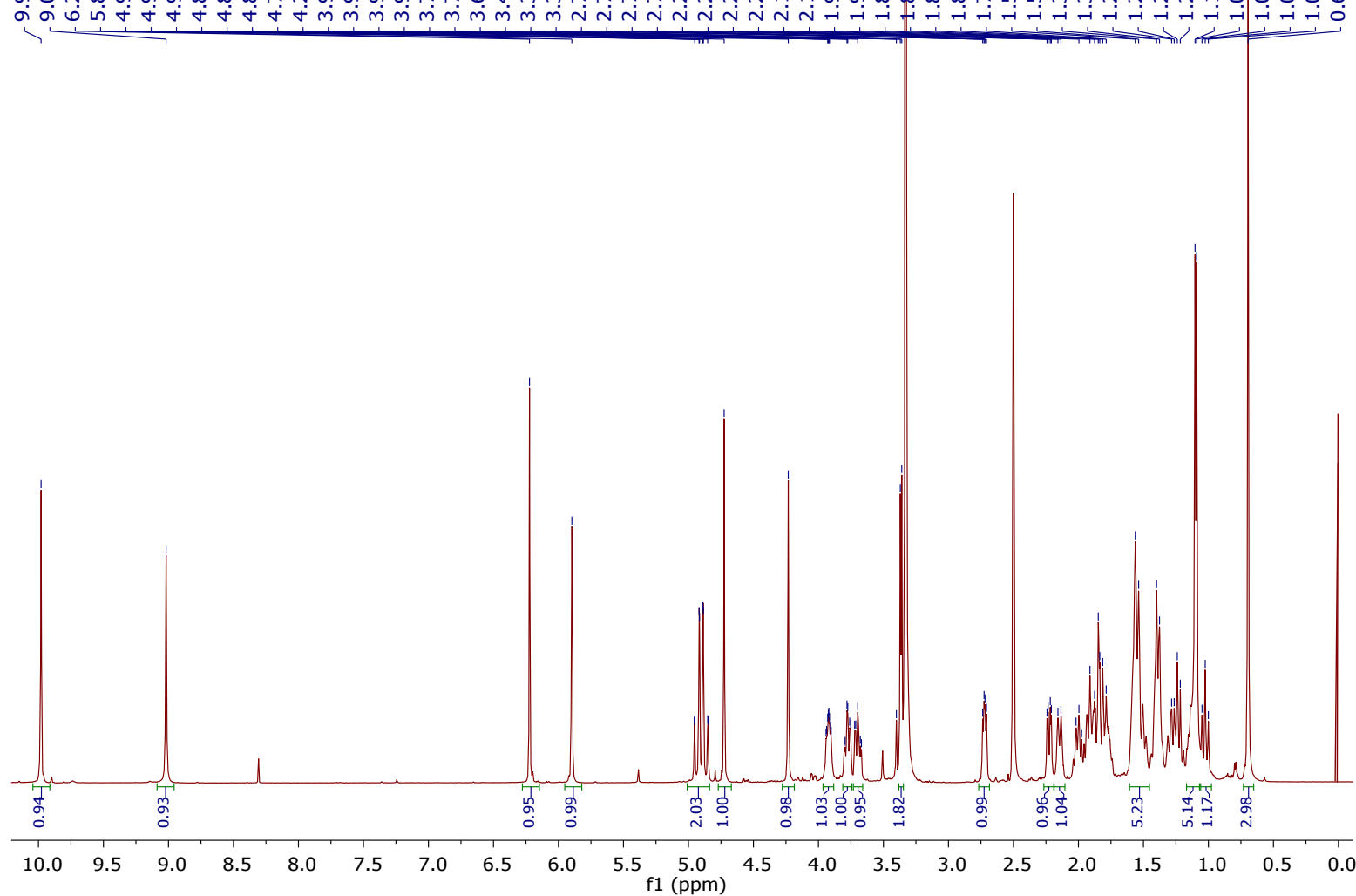

Figure S1. ${ }^{1} \mathrm{H}$ NMR spectrum of compound $1\left(500 \mathrm{MHz}, \mathrm{DMSO}-d_{6}\right)$

1
$\stackrel{0}{0}$
$\stackrel{0}{0}$

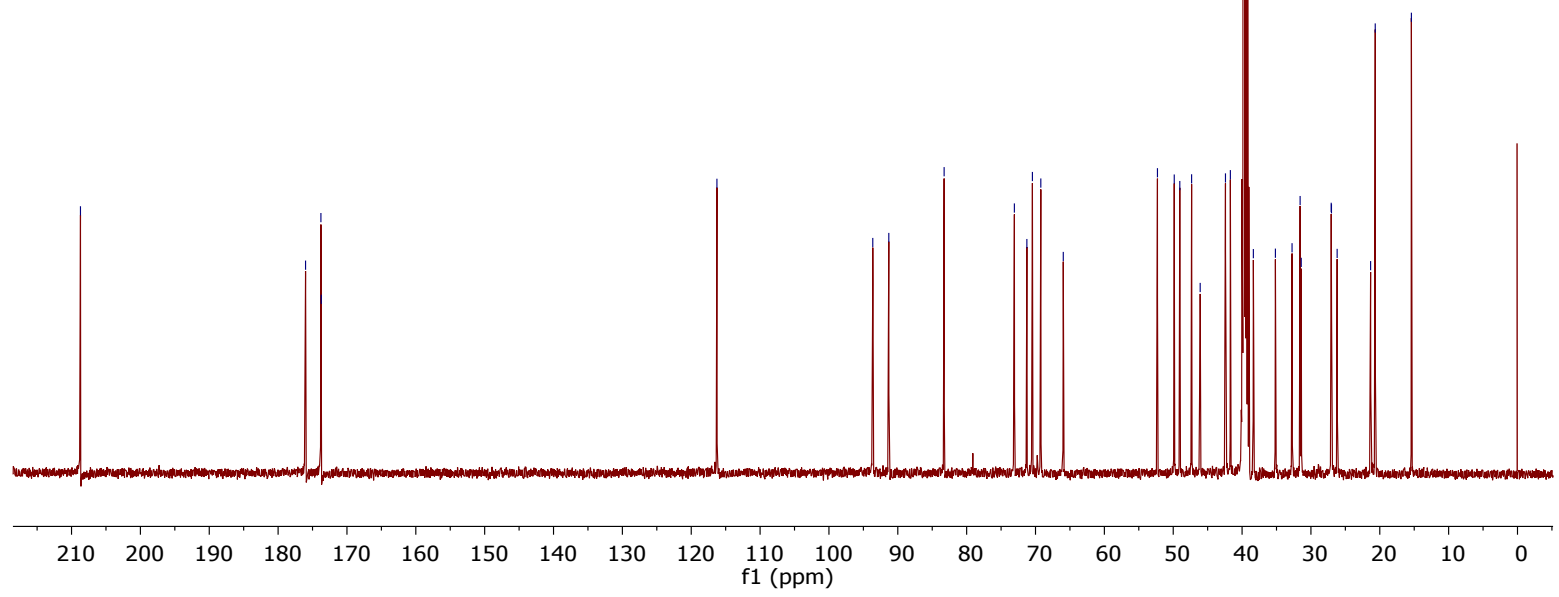

Figure S2. ${ }^{13} \mathrm{C}$ NMR spectrum of compound $1\left(125 \mathrm{MHz}, \mathrm{DMSO}-d_{6}\right)$ 


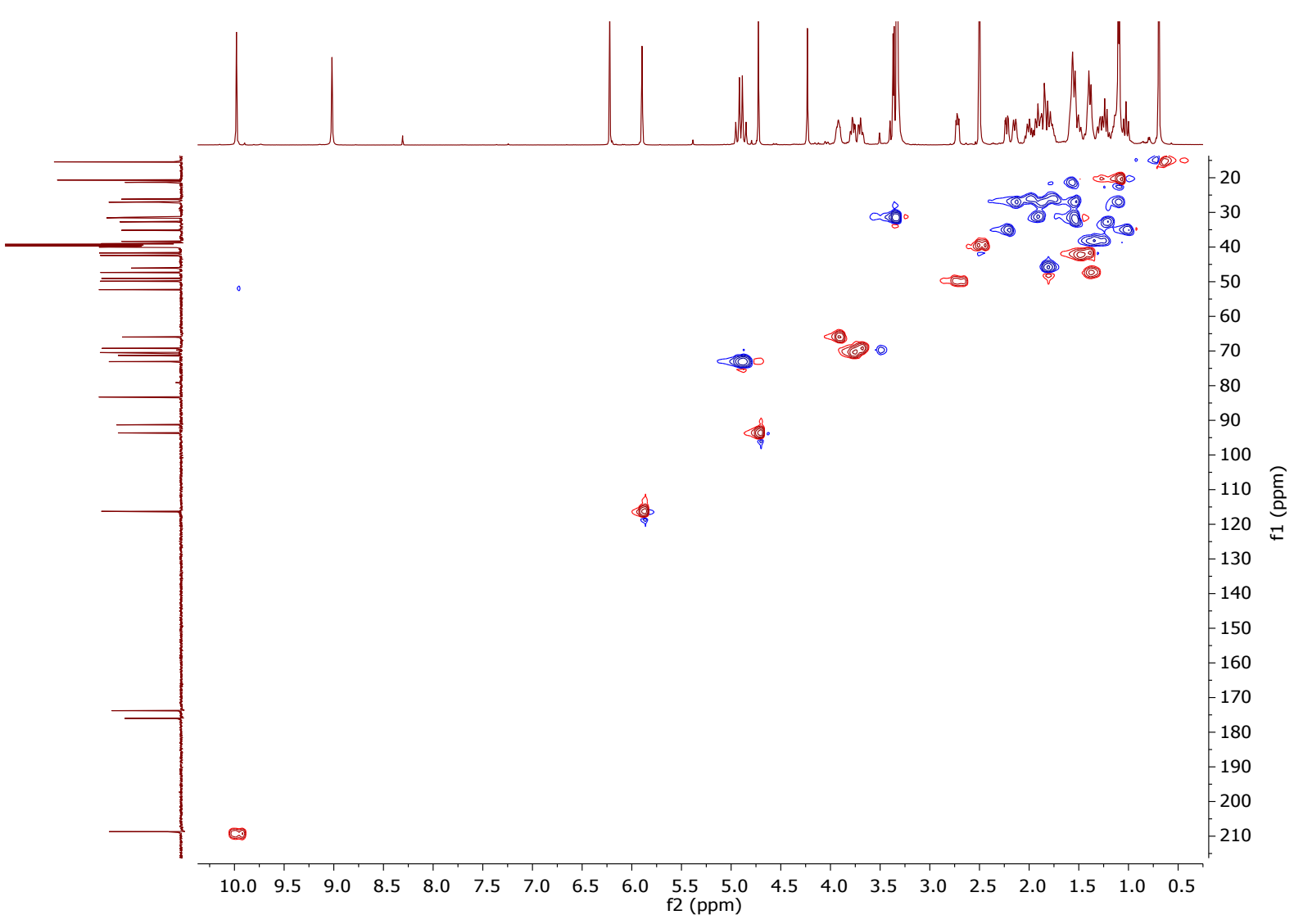

Figure S3. HSQC NMR spectrum of compound 1

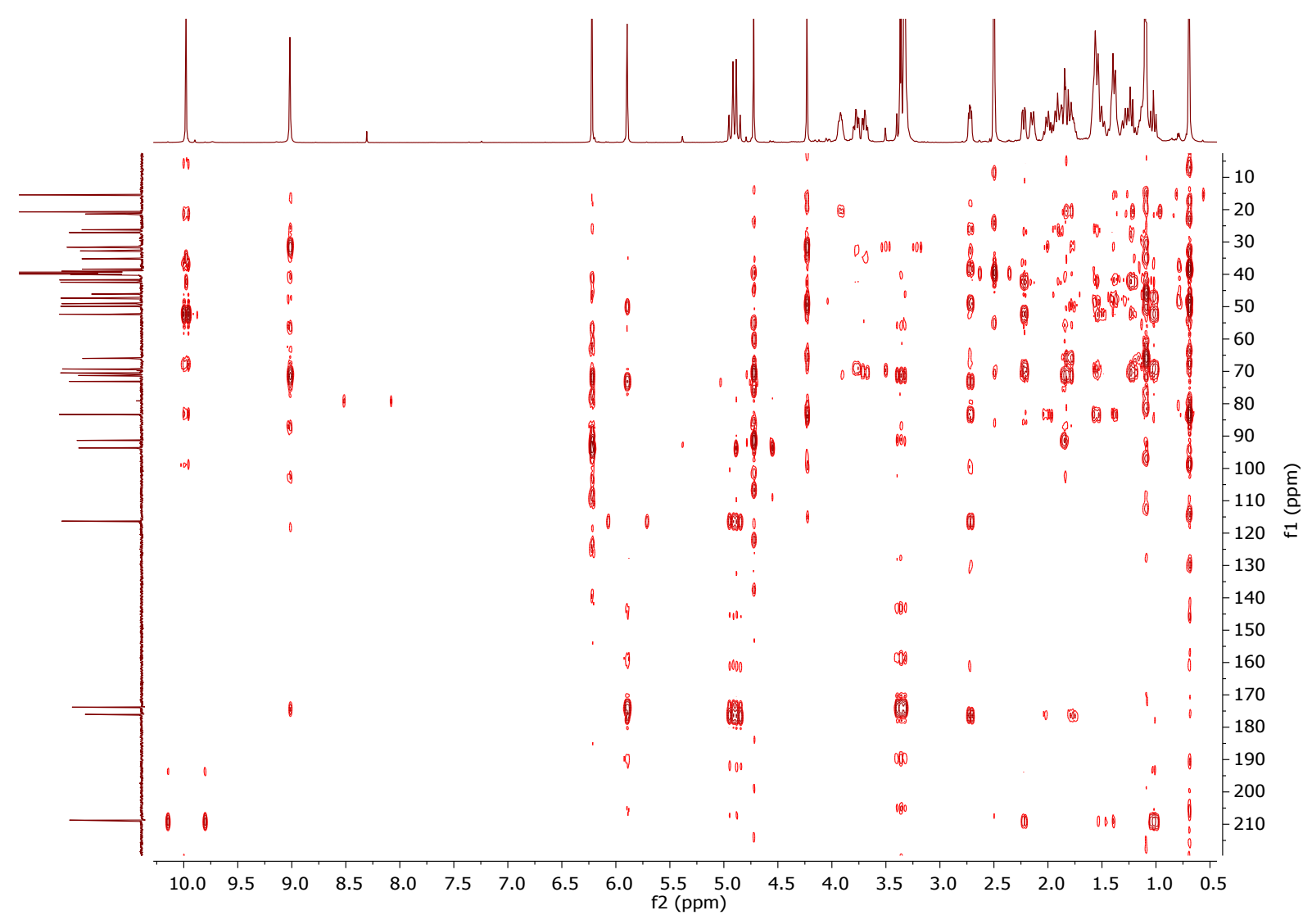

Figure S4. HMBC NMR spectrum of compound 1 


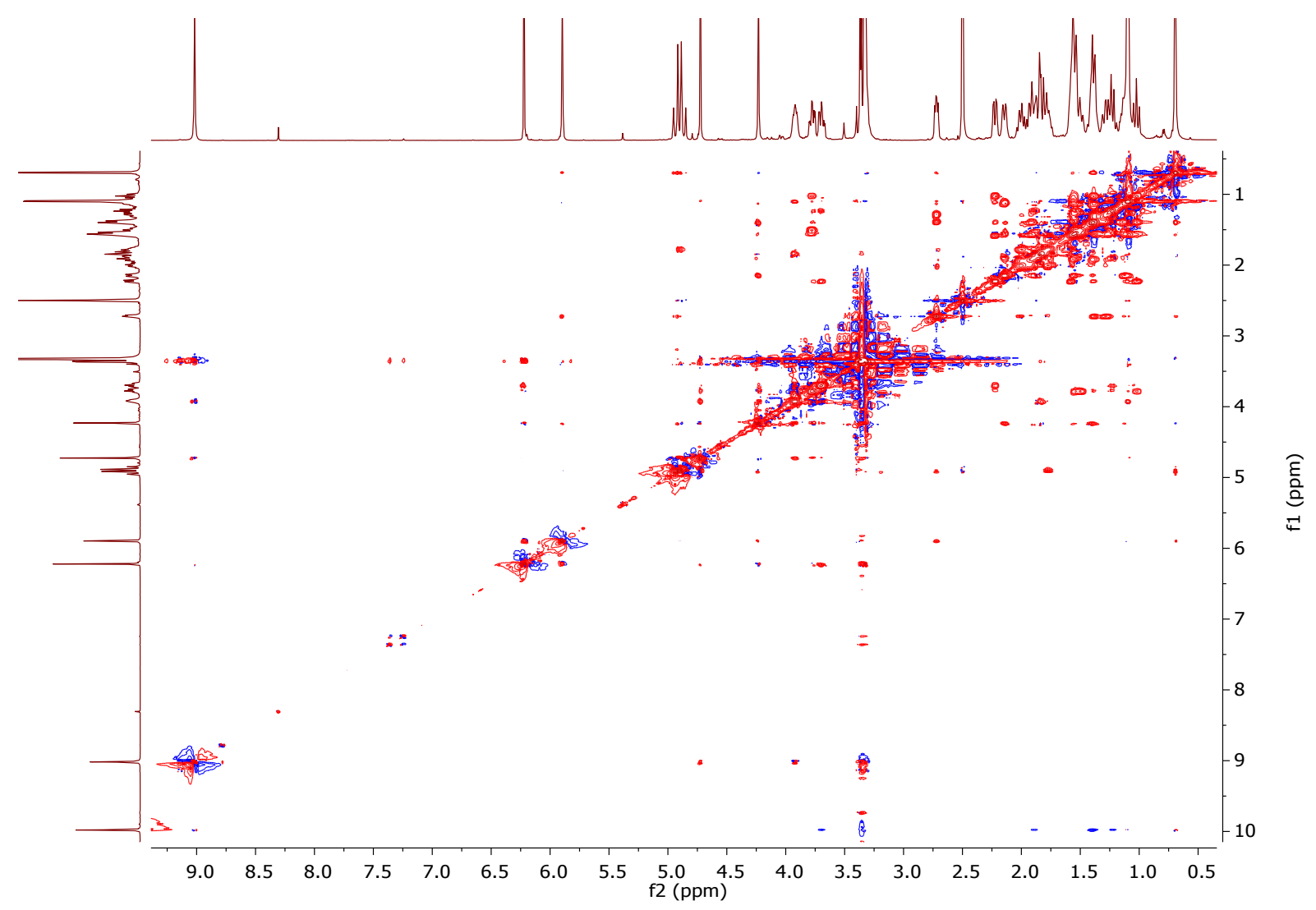

Figure S5. NOESY NMR spectrum of compound 1 


\section{Display Report}

Analysis Info

Analysis Name

Method

Sample Name

Comment
Acquisition Date $\quad$ 12/9/2013 7:03:36 PM

D:IDataldata DMM 2013IDK18_1-D,4_01_8933.d

protein my mass tb.m

DK18

Operator Mai

Instrument micrOTOF-Q 10187
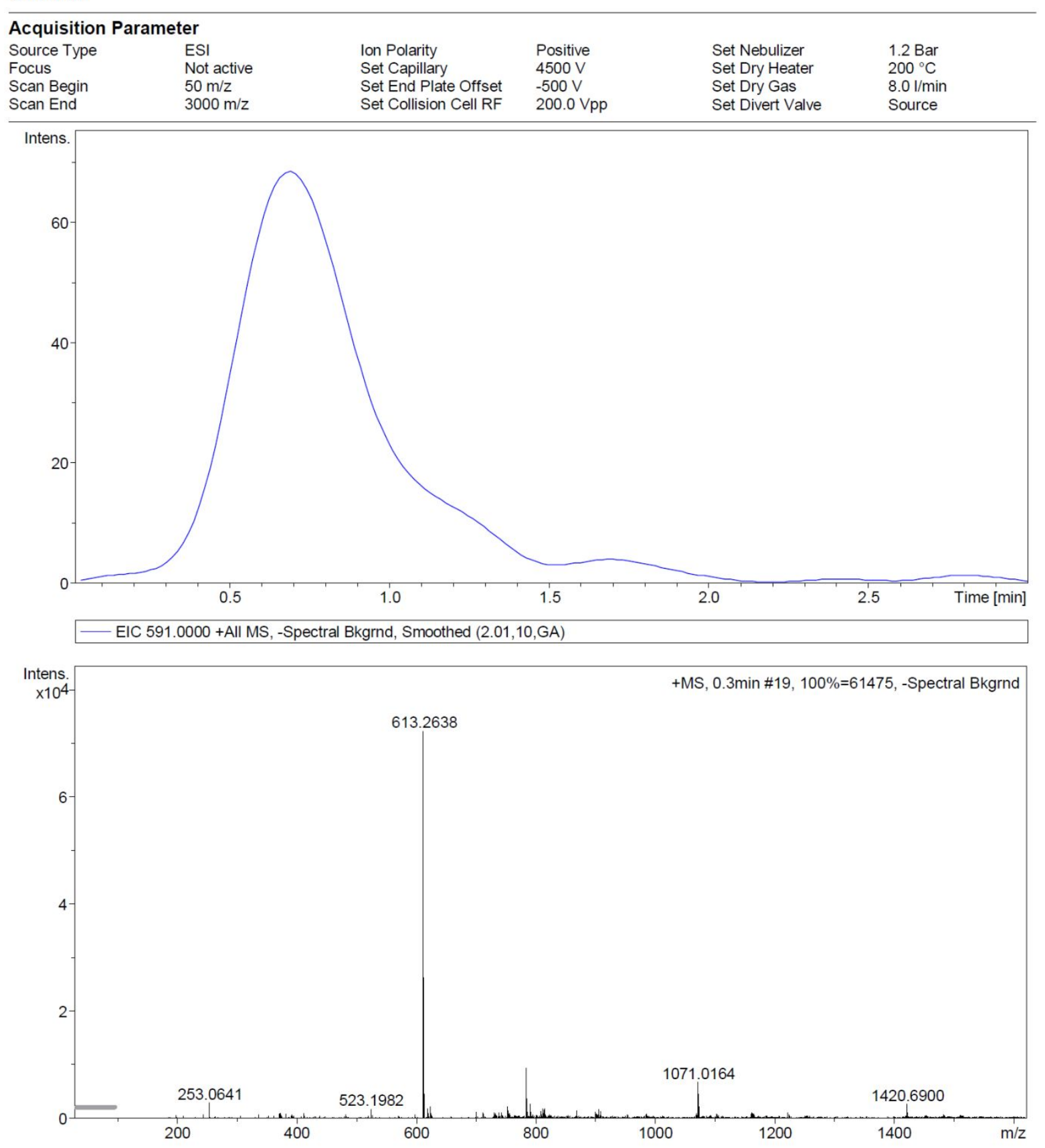

Figure S6. HR-ESIMS of compound 1 


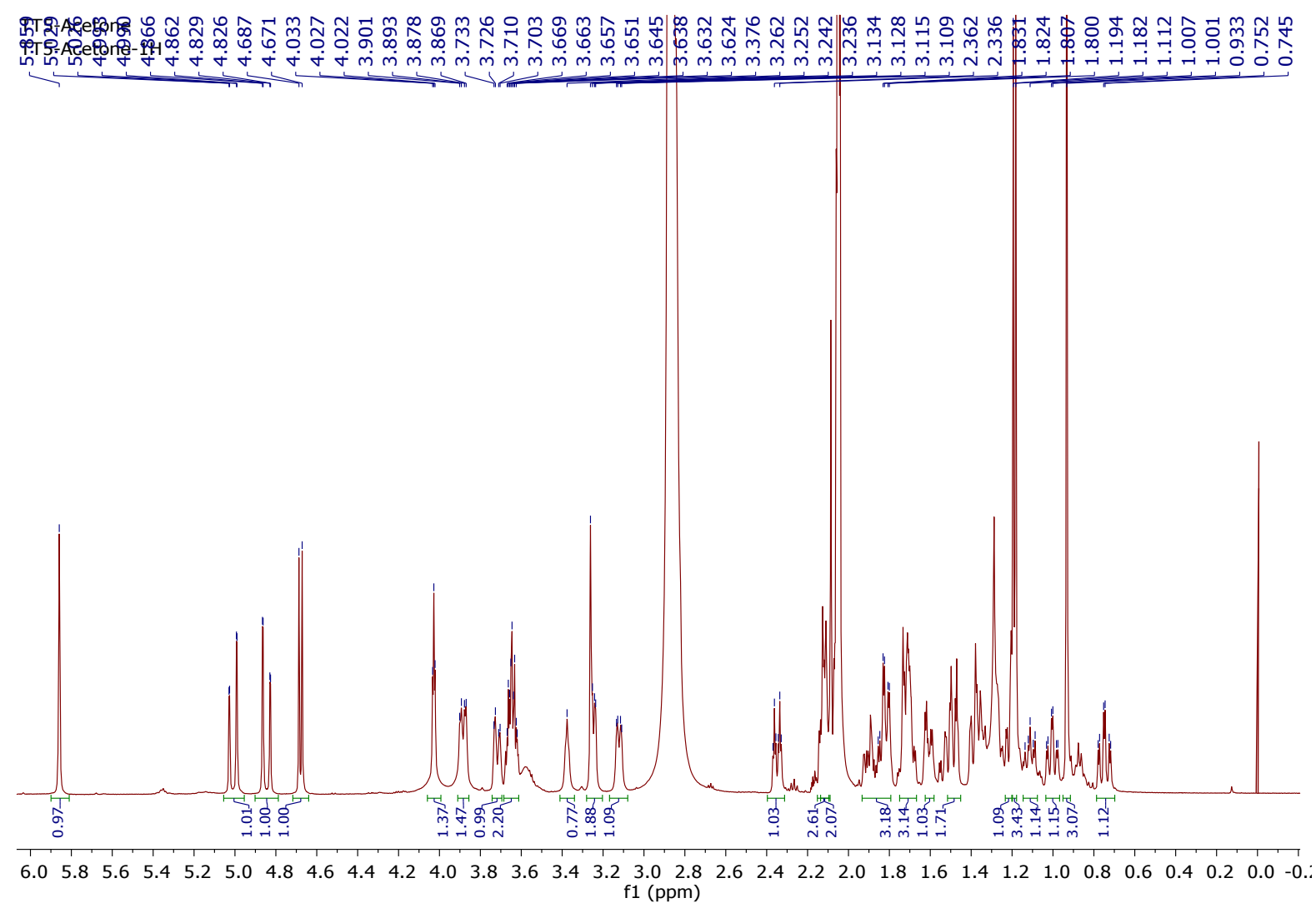

Figure S7. ${ }^{1} \mathrm{H}$ NMR spectrum of compound $2\left(500 \mathrm{MHz}\right.$, acetone- $\left.d_{6}\right)$

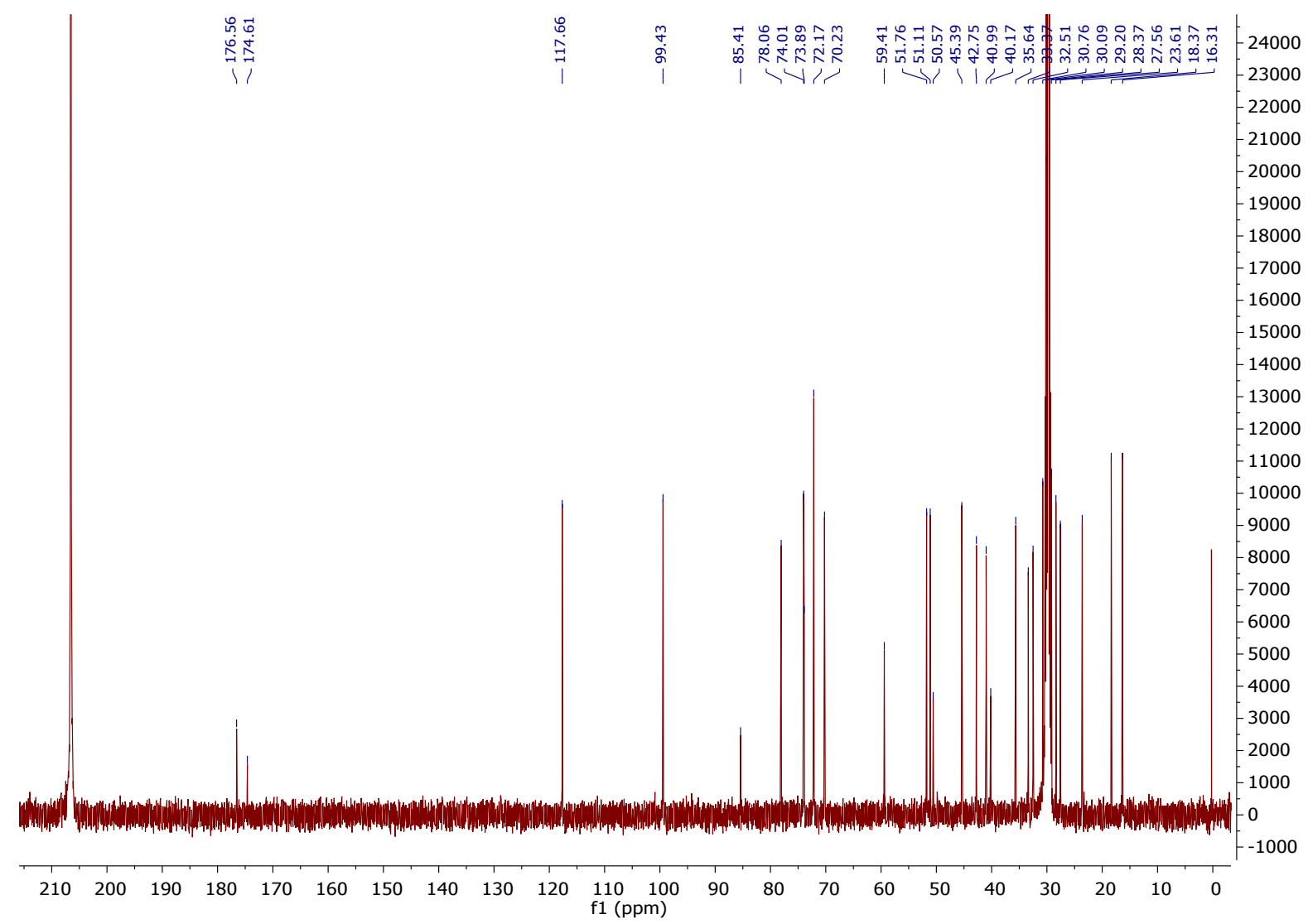

Figure S8. ${ }^{13} \mathrm{C}$ NMR spectrum of compound 2 (125 MHz, acetone- $d_{6}$ ) 


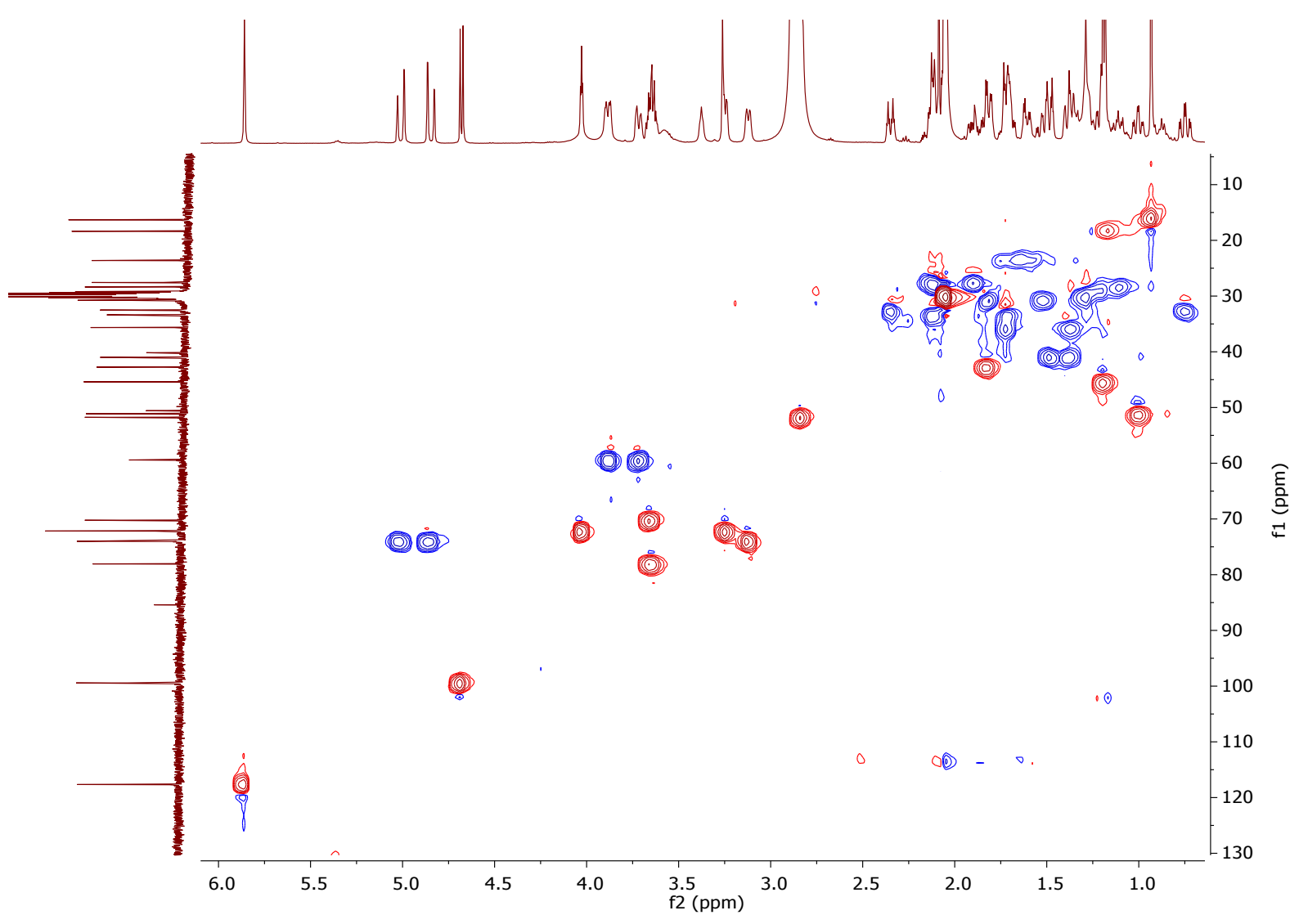

Figure S9. HSQC NMR spectrum of compound 2

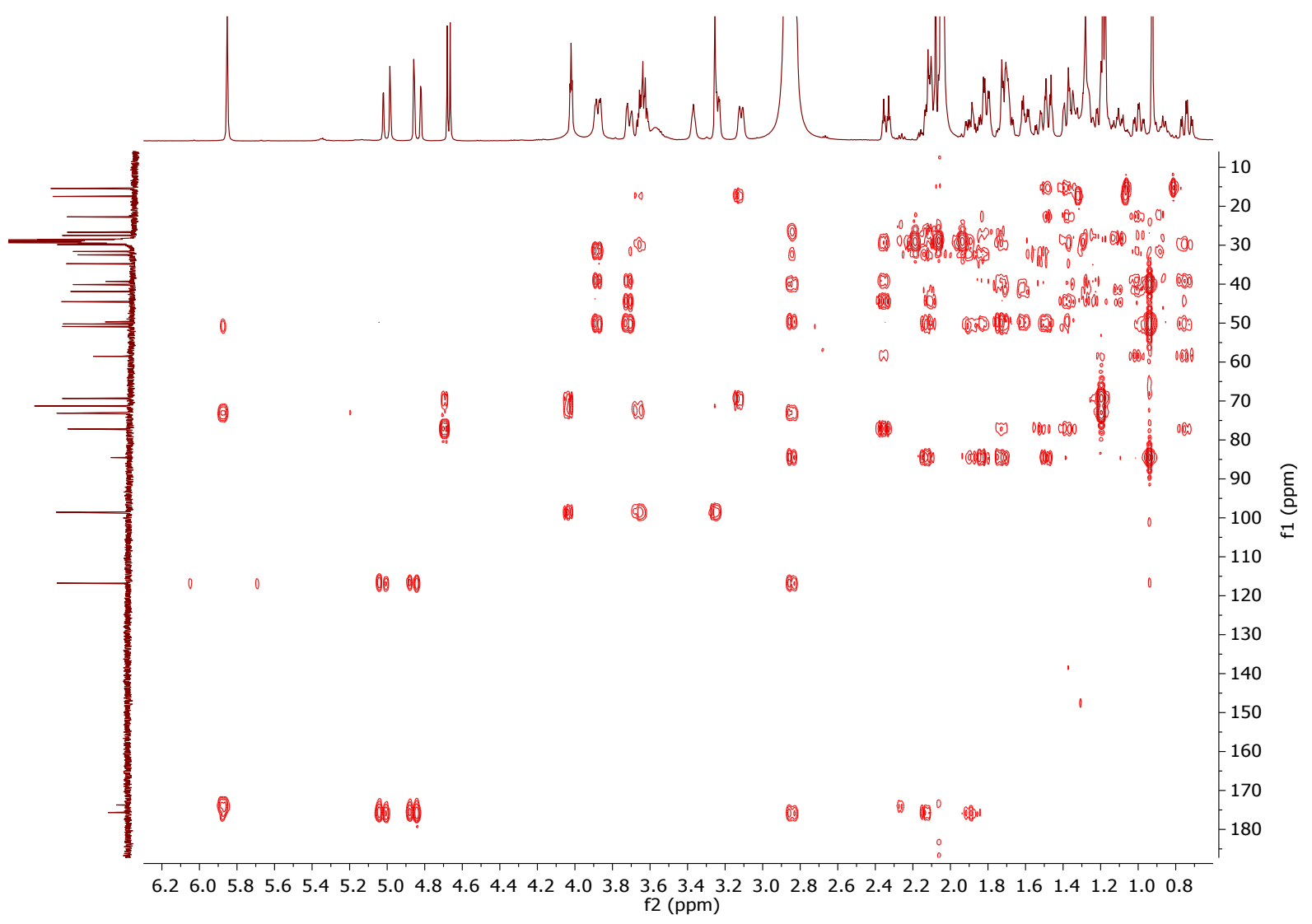

Figure S10. HMBC NMR spectrum of compound 2 


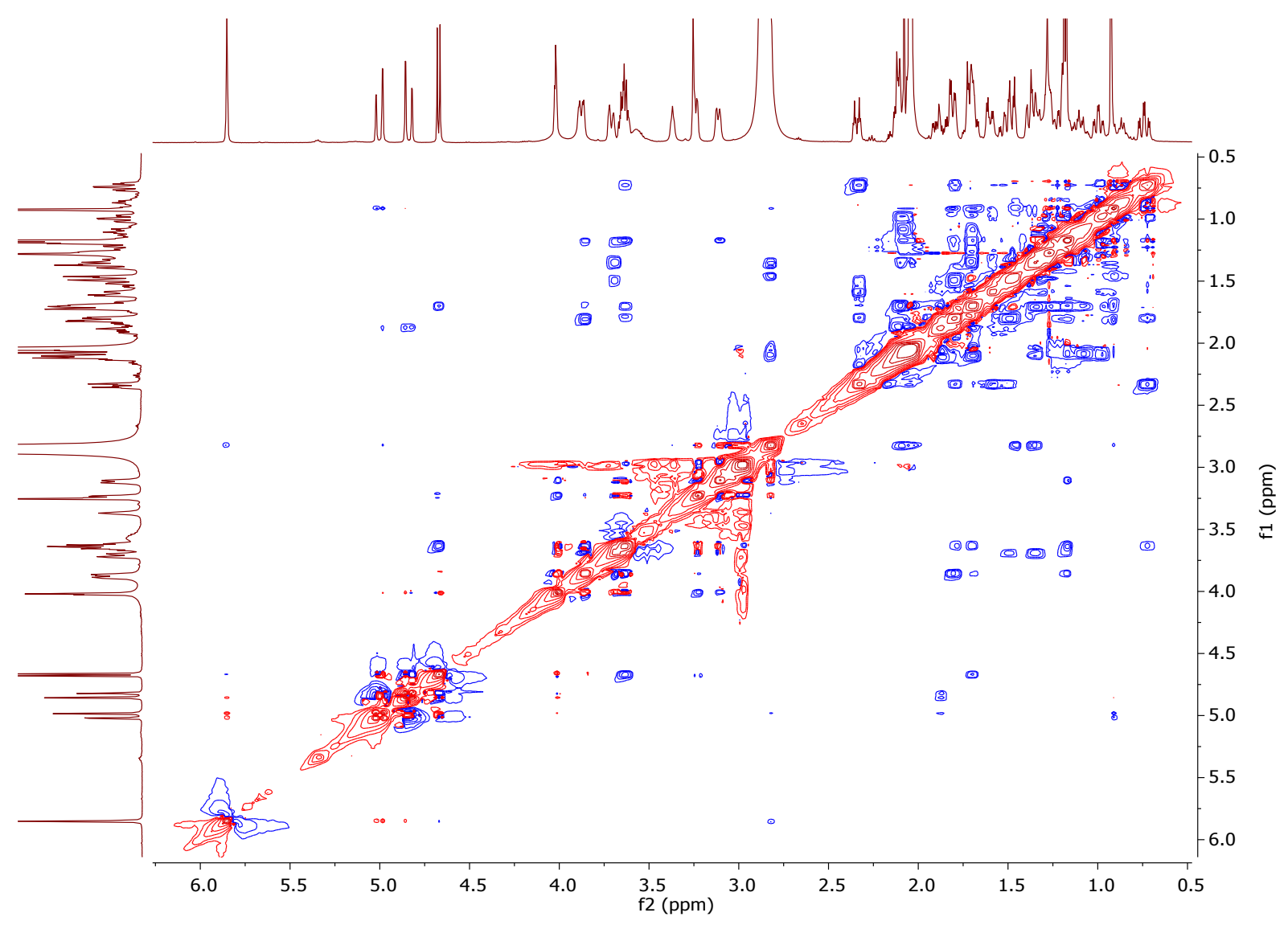

Figure S11. NOESY NMR spectrum of compound 2 
Display Report
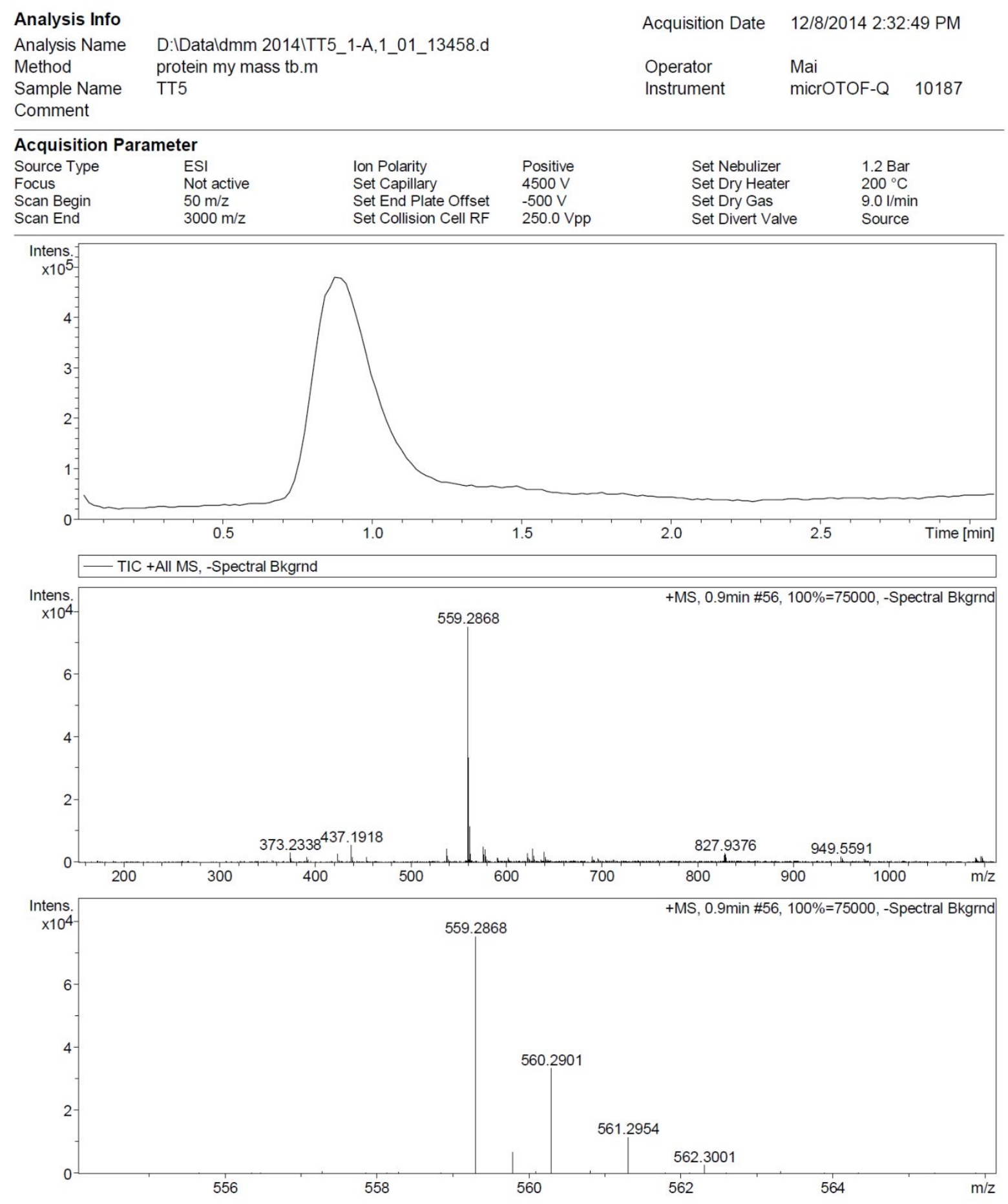

Figure S12. HR-ESIMS of compound 2 


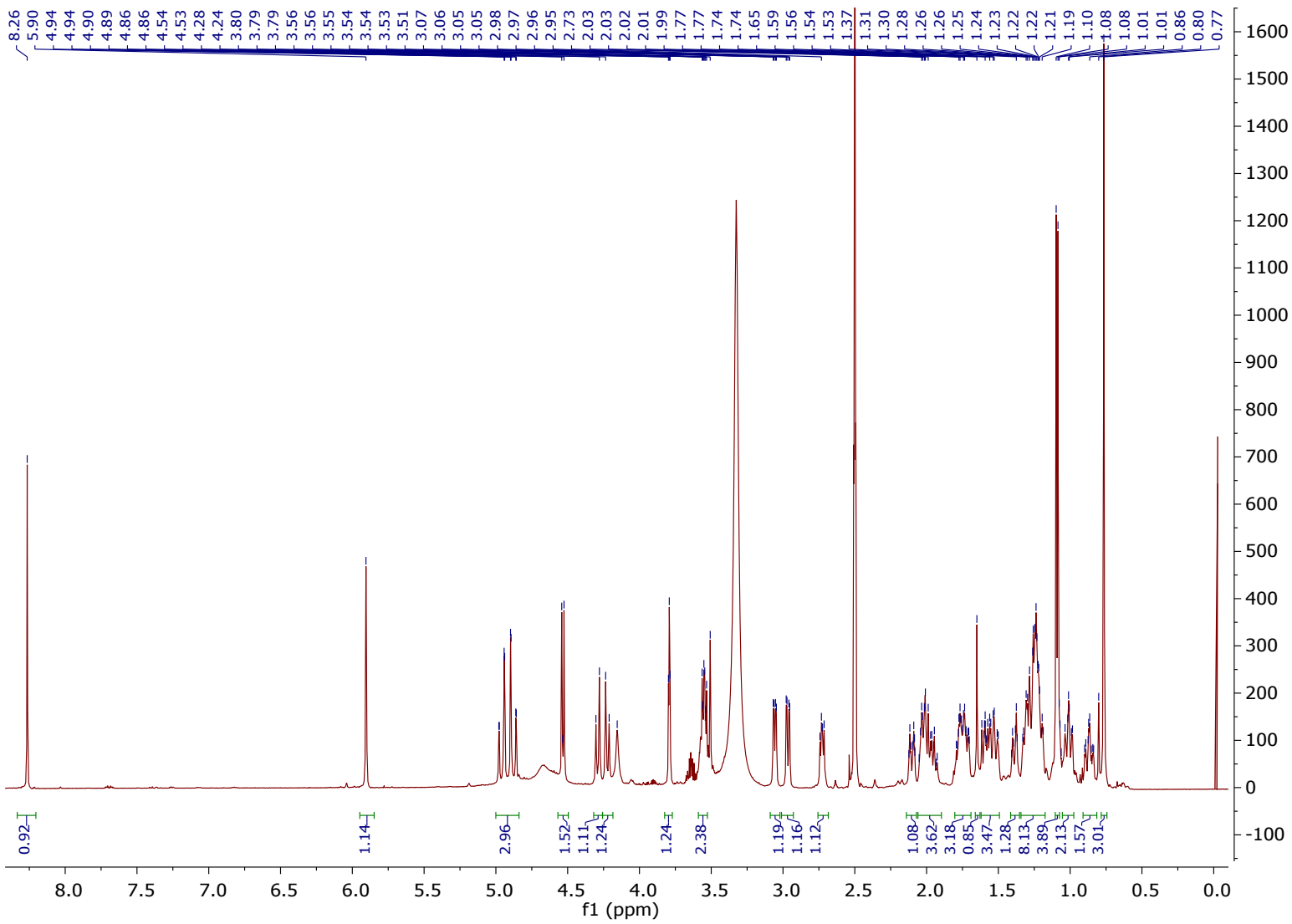

Figure S13. ${ }^{1} \mathrm{H}$ NMR spectrum of compound 3 (500 MHz, DMSO- $d_{6}$ )

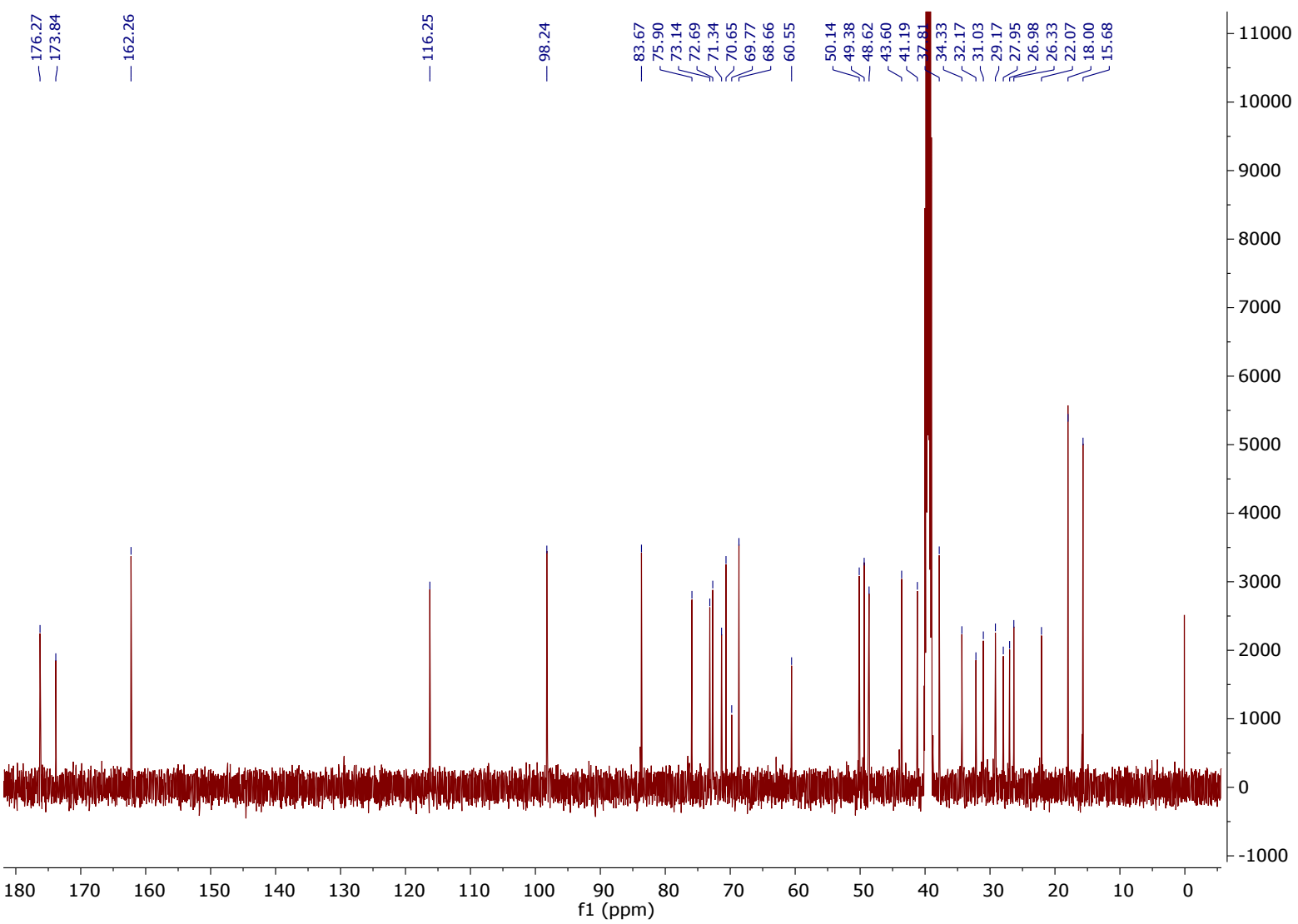

Figure S14. ${ }^{13} \mathrm{C}$ NMR spectrum of compound $3\left(125 \mathrm{MHz}\right.$, DMSO- $\left.d_{6}\right)$ 


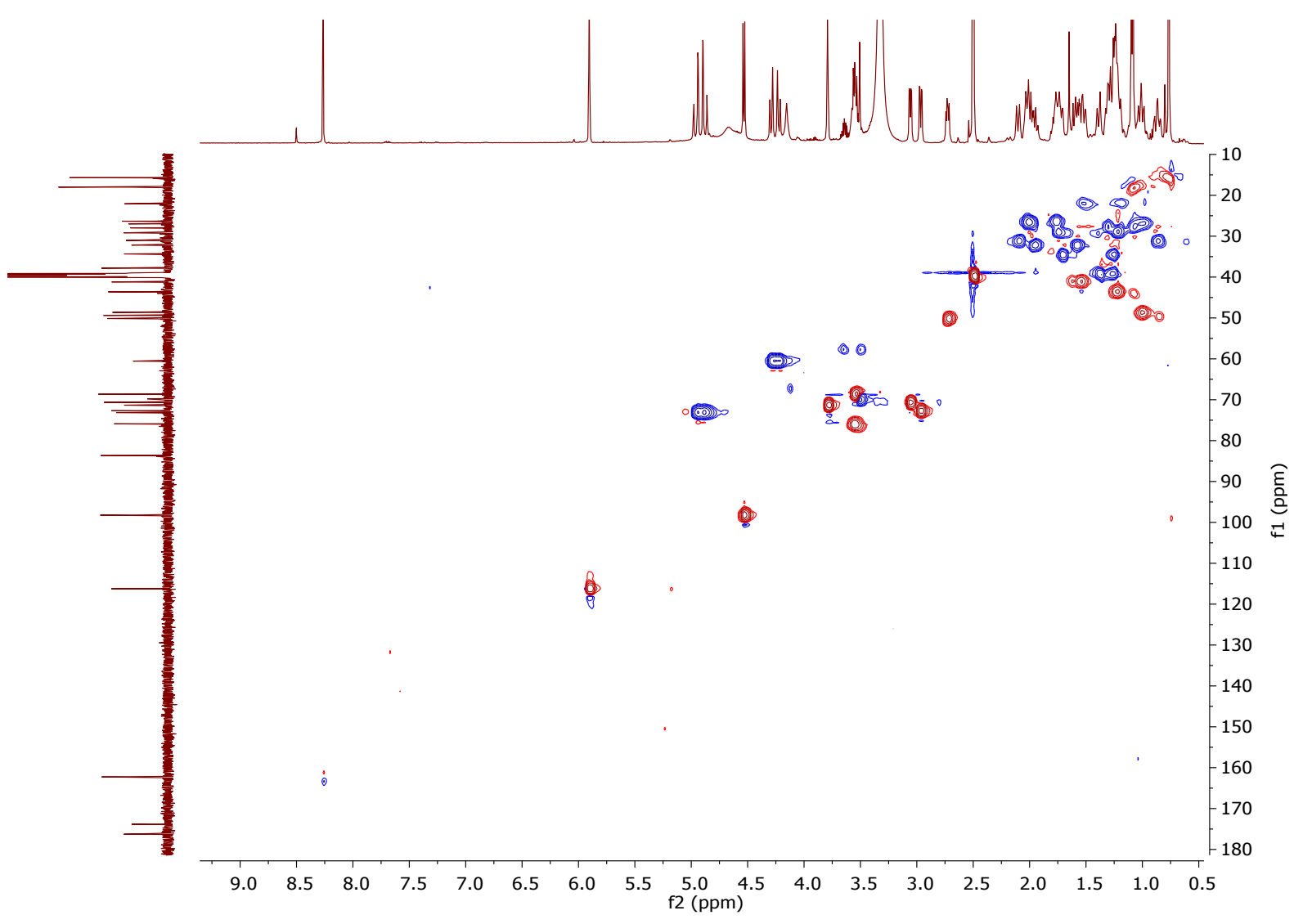

Figure S15. HSQC NMR spectrum of compound $\mathbf{3}$

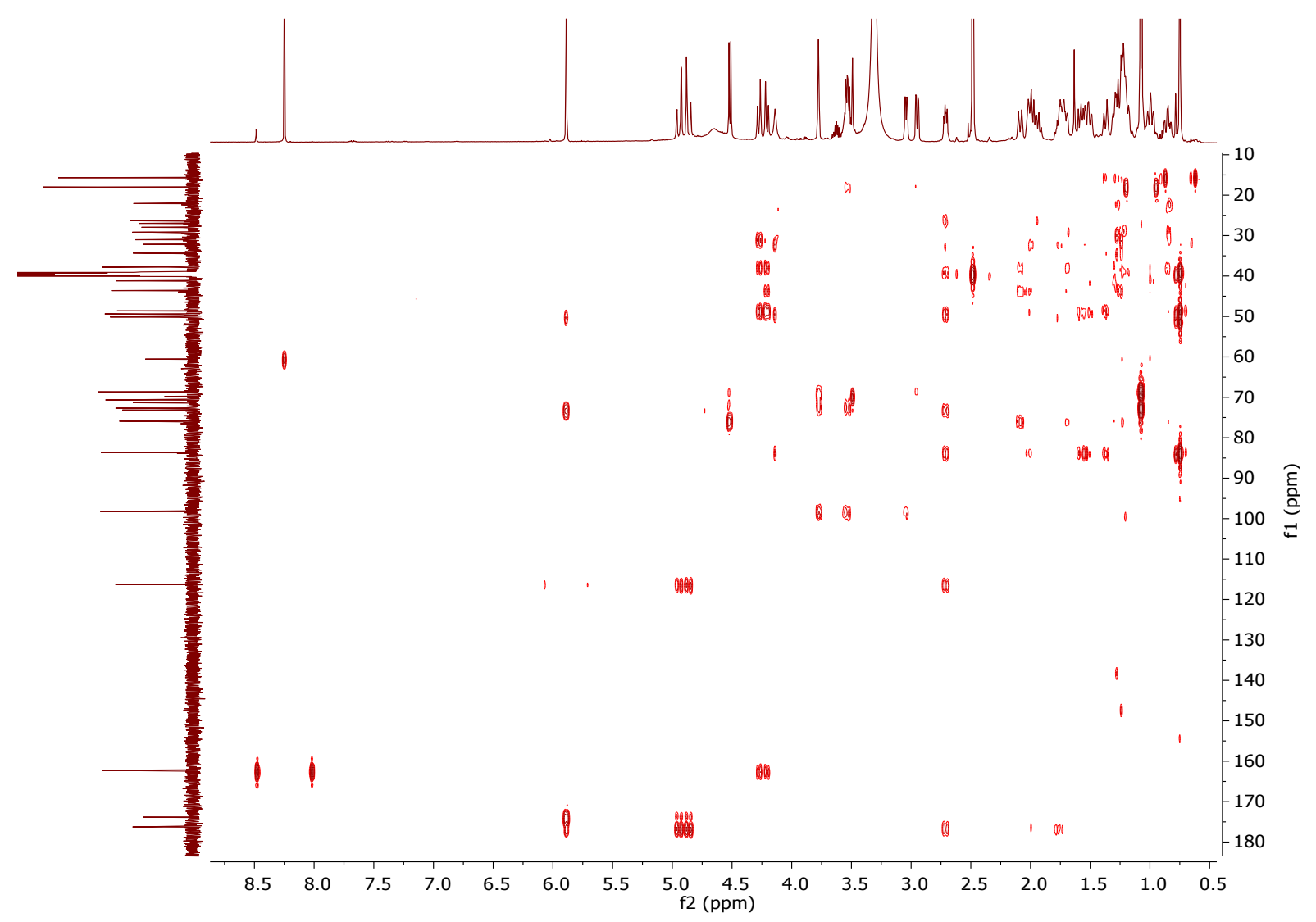

Figure S16. HMBC NMR spectrum of compound 3 


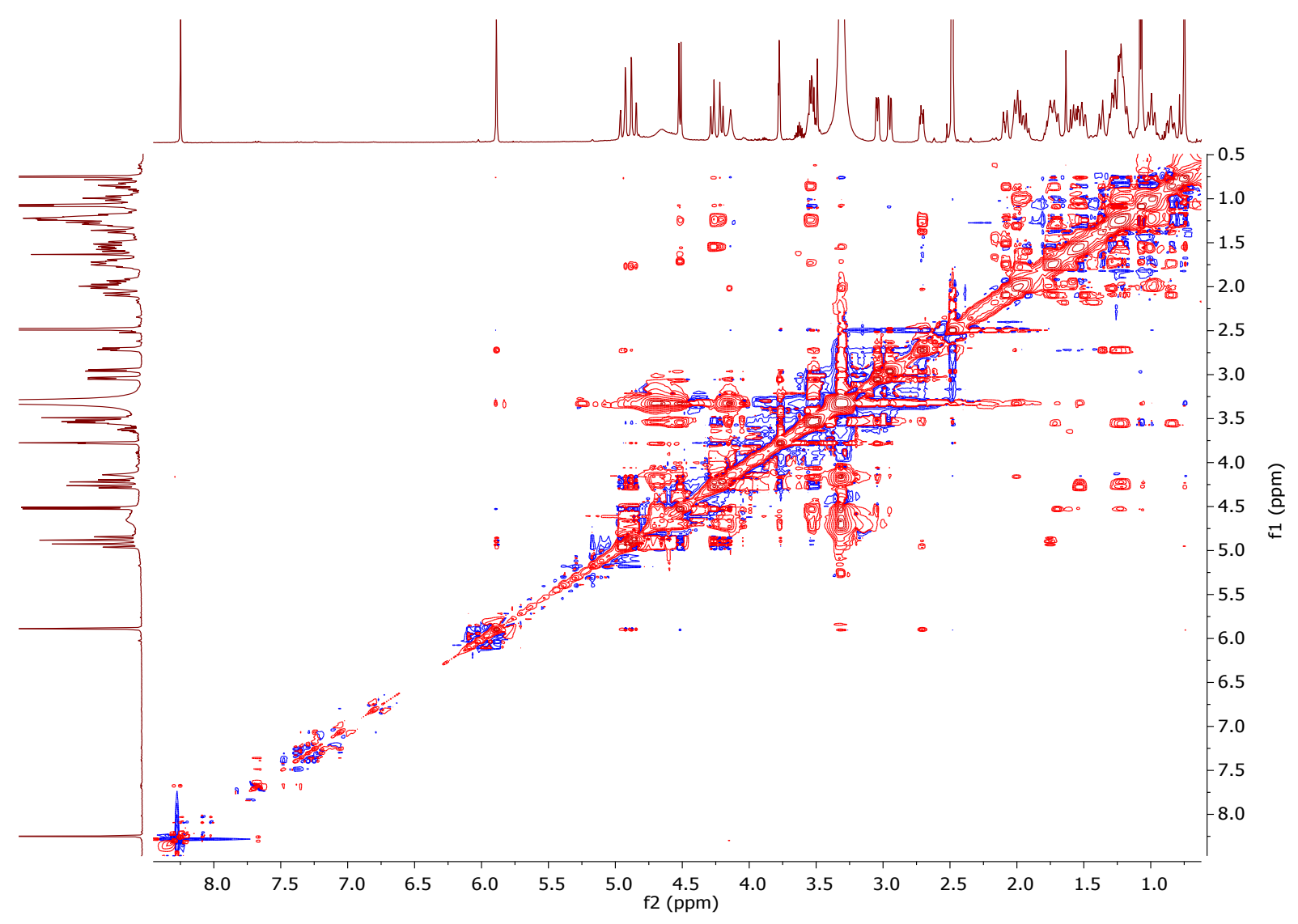

Figure S17. NOESY NMR spectrum of compound 3 


\section{Display Report}

Analysis Info

Analysis Name

Method

Sample Name

Comment
D.Dataldmm 2015\AK13_1-E 4 _ 01 15611.d

dmm.m

AK13
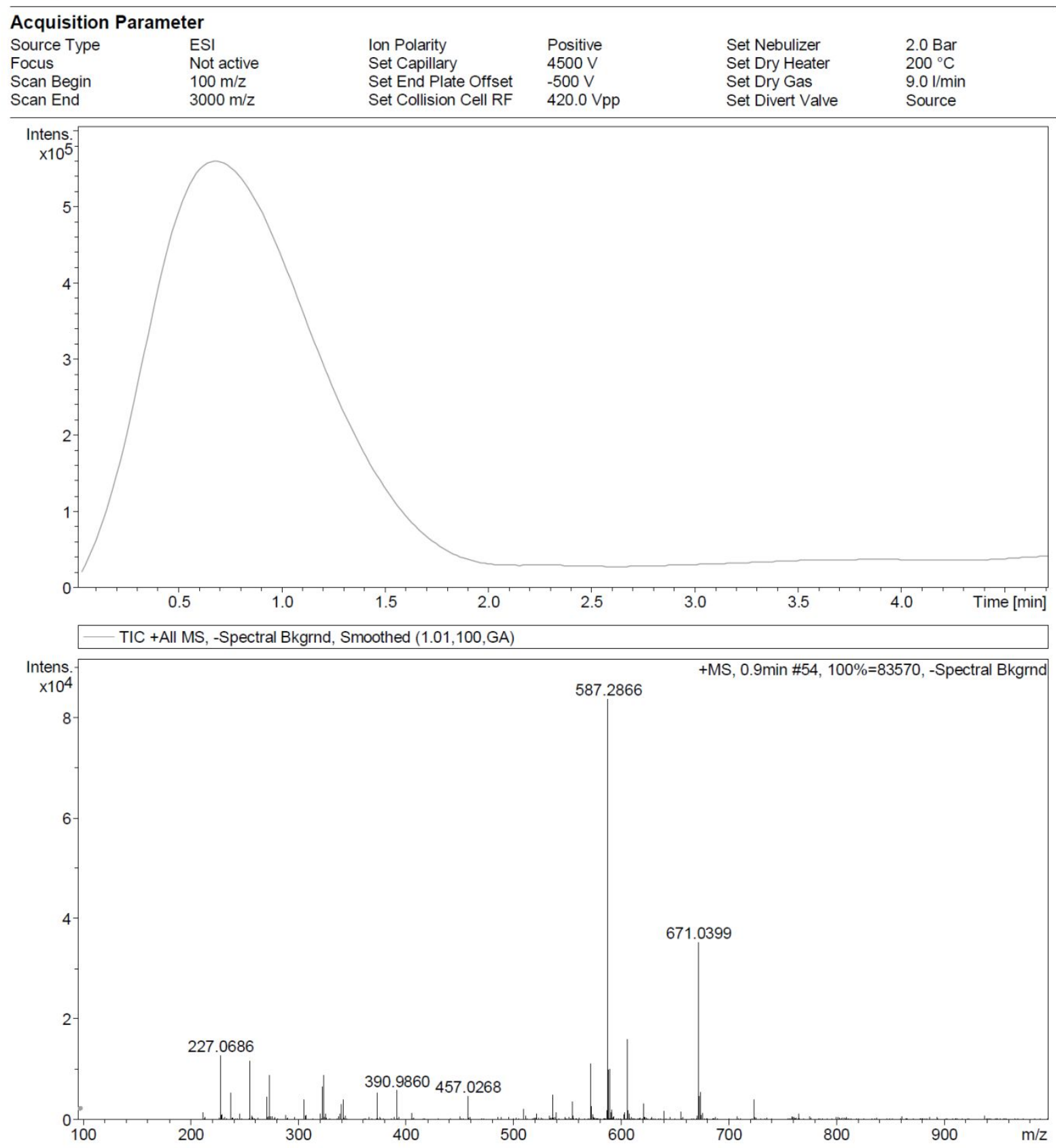

Bruker Compass DataAnalysis 4.0
4/17/2015 2:45:11 PM

$\mathrm{Ma}$

micrOTOF-Q 10187

Figure S18. HR-ESIMS of compound 3 


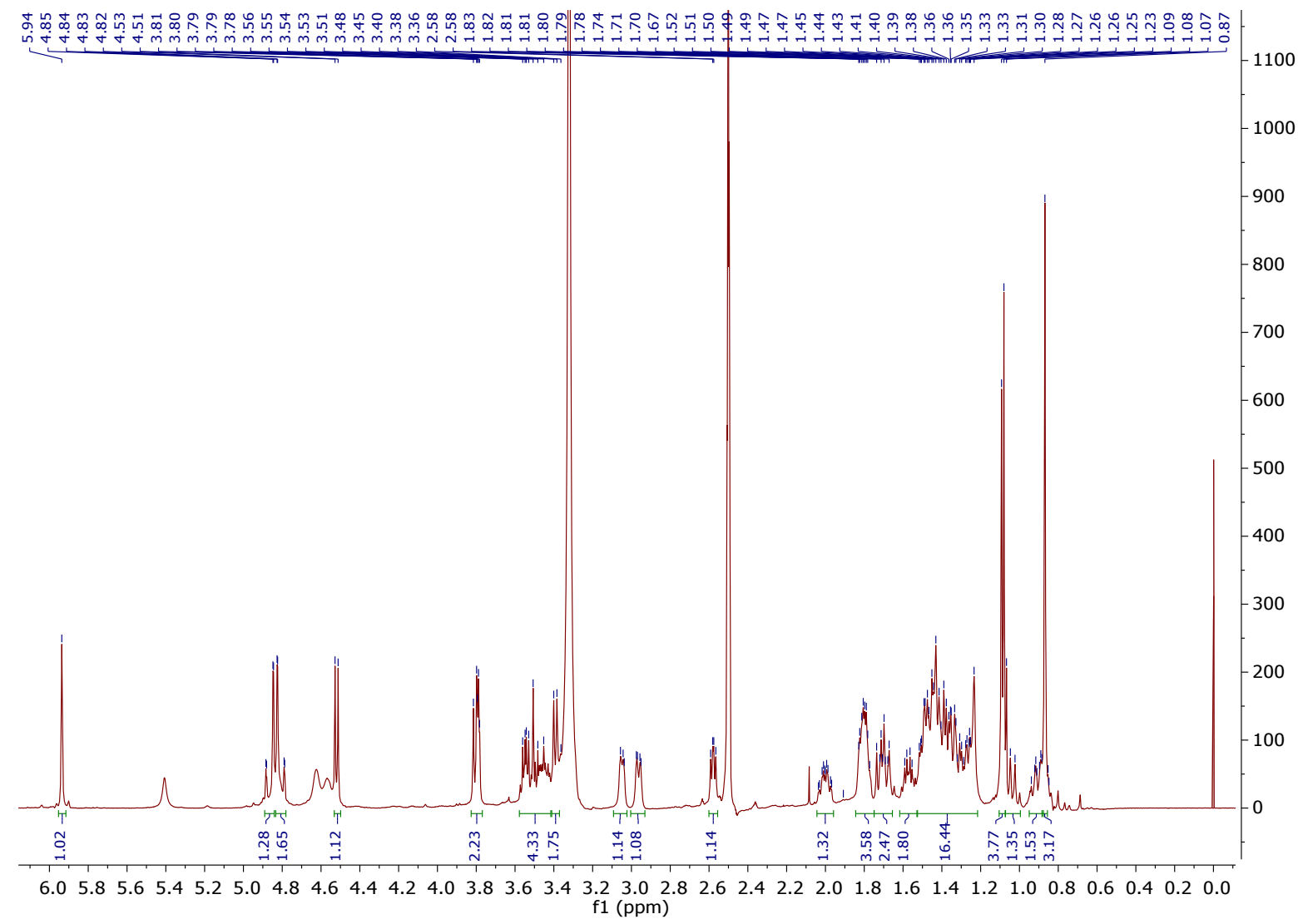

Figure S19. ${ }^{1} \mathrm{H}$ NMR spectrum of compound 4 (500 MHz, DMSO- $d_{6}$ )

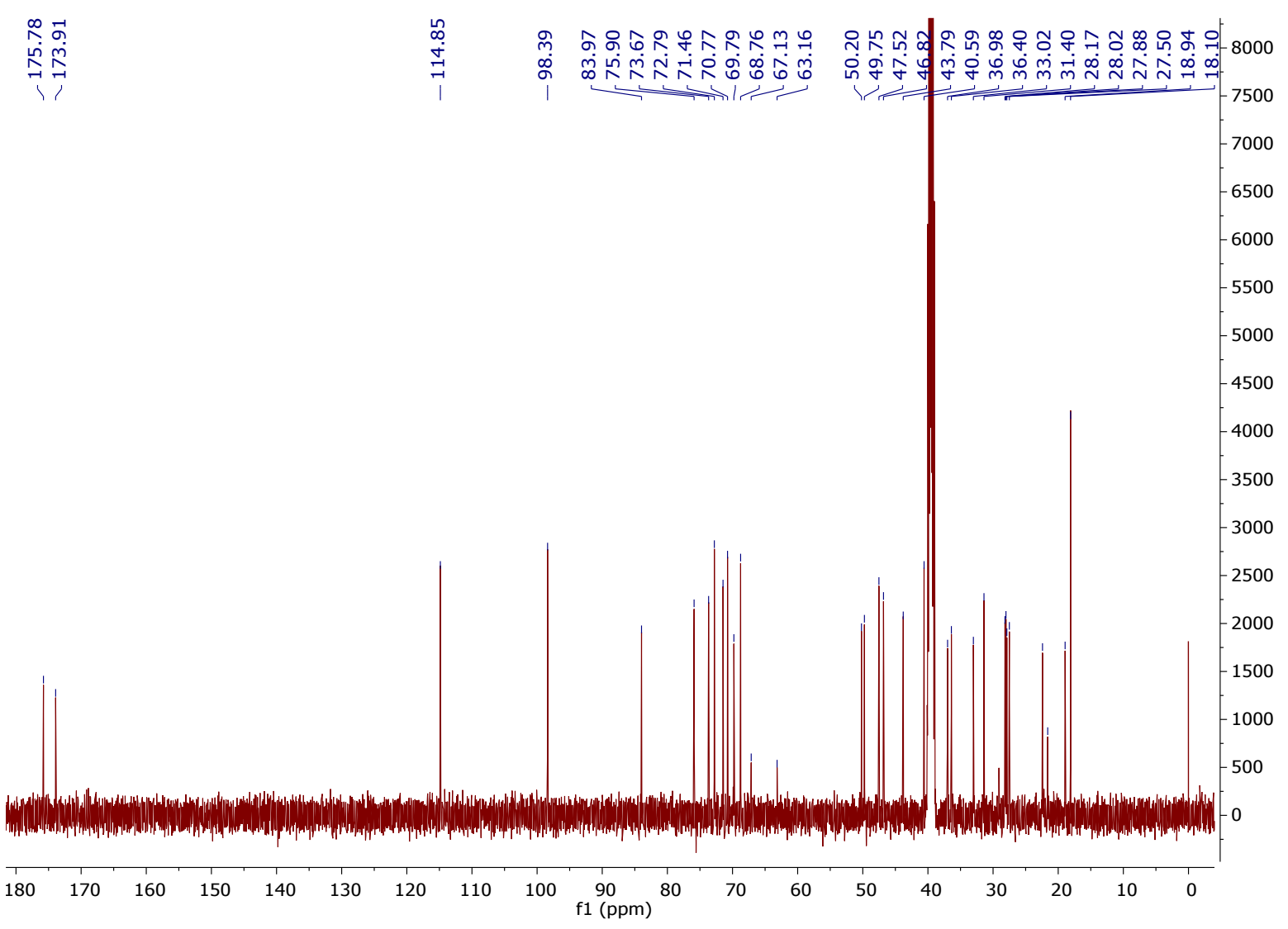

Figure S20. ${ }^{13} \mathrm{C}$ NMR spectrum of compound $4\left(125 \mathrm{MHz}\right.$, DMSO- $\left.d_{6}\right)$ 


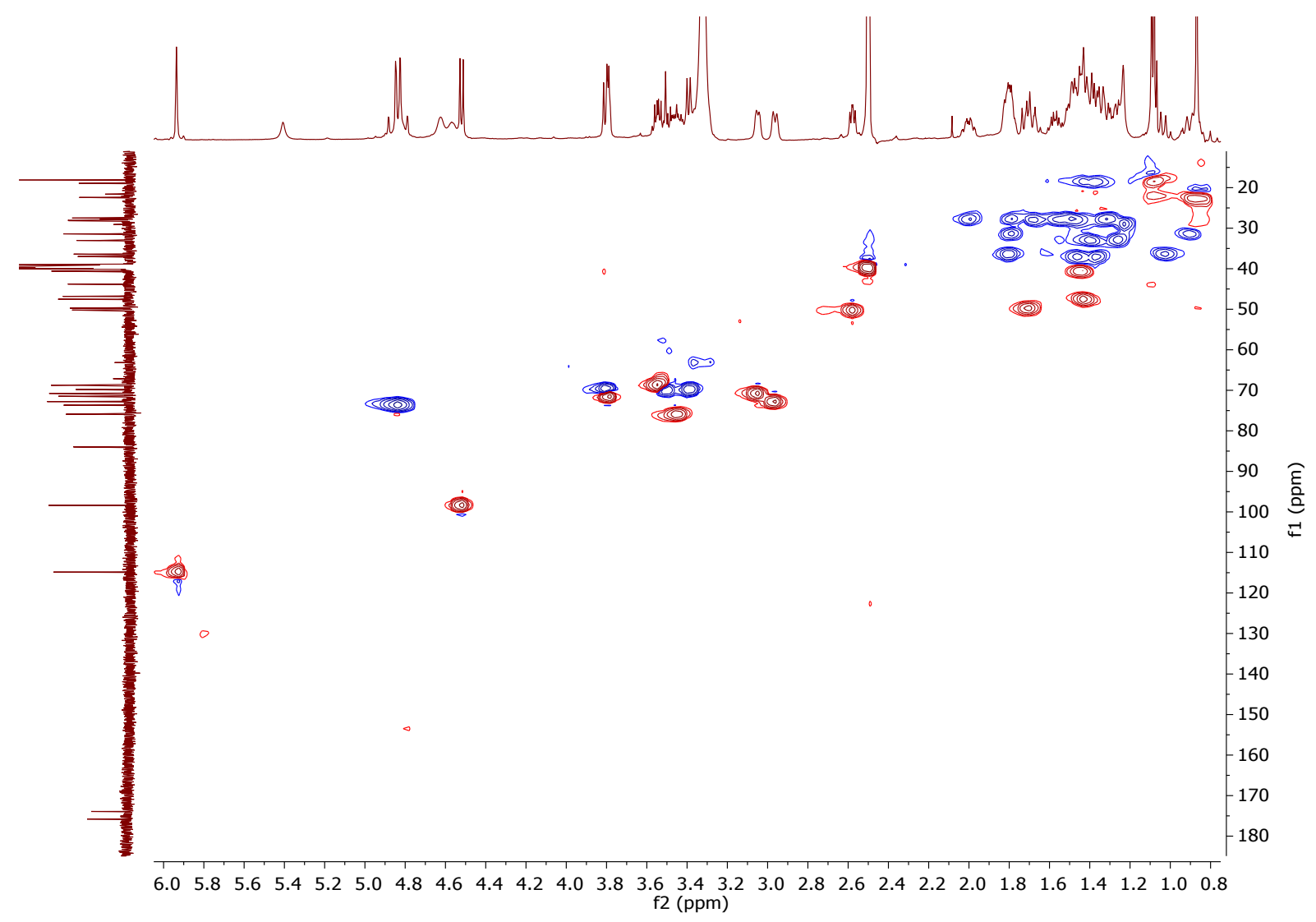

Figure S21. HSQC NMR spectrum of compound 4

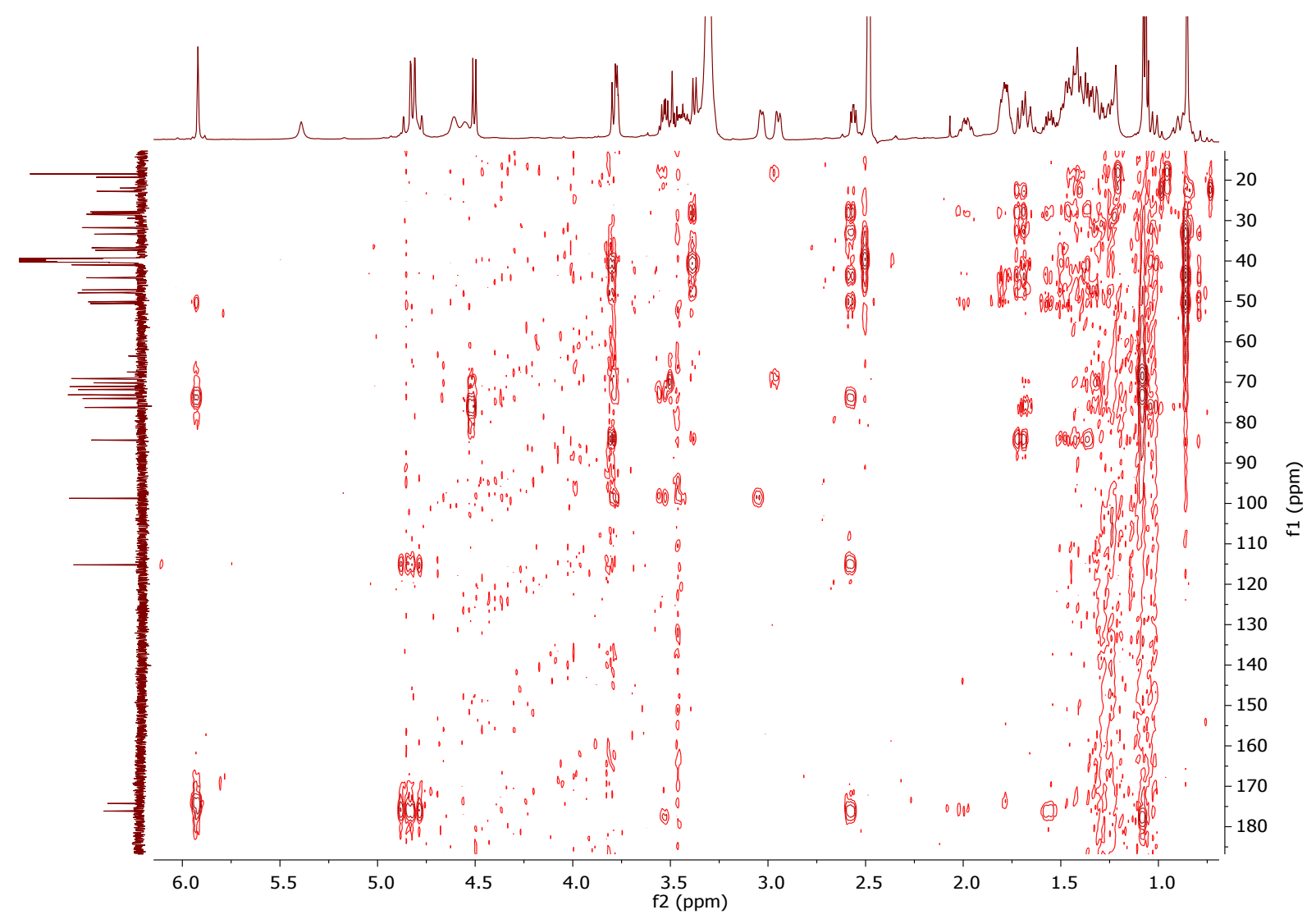

Figure S22. HMBC NMR spectrum of compound 4 


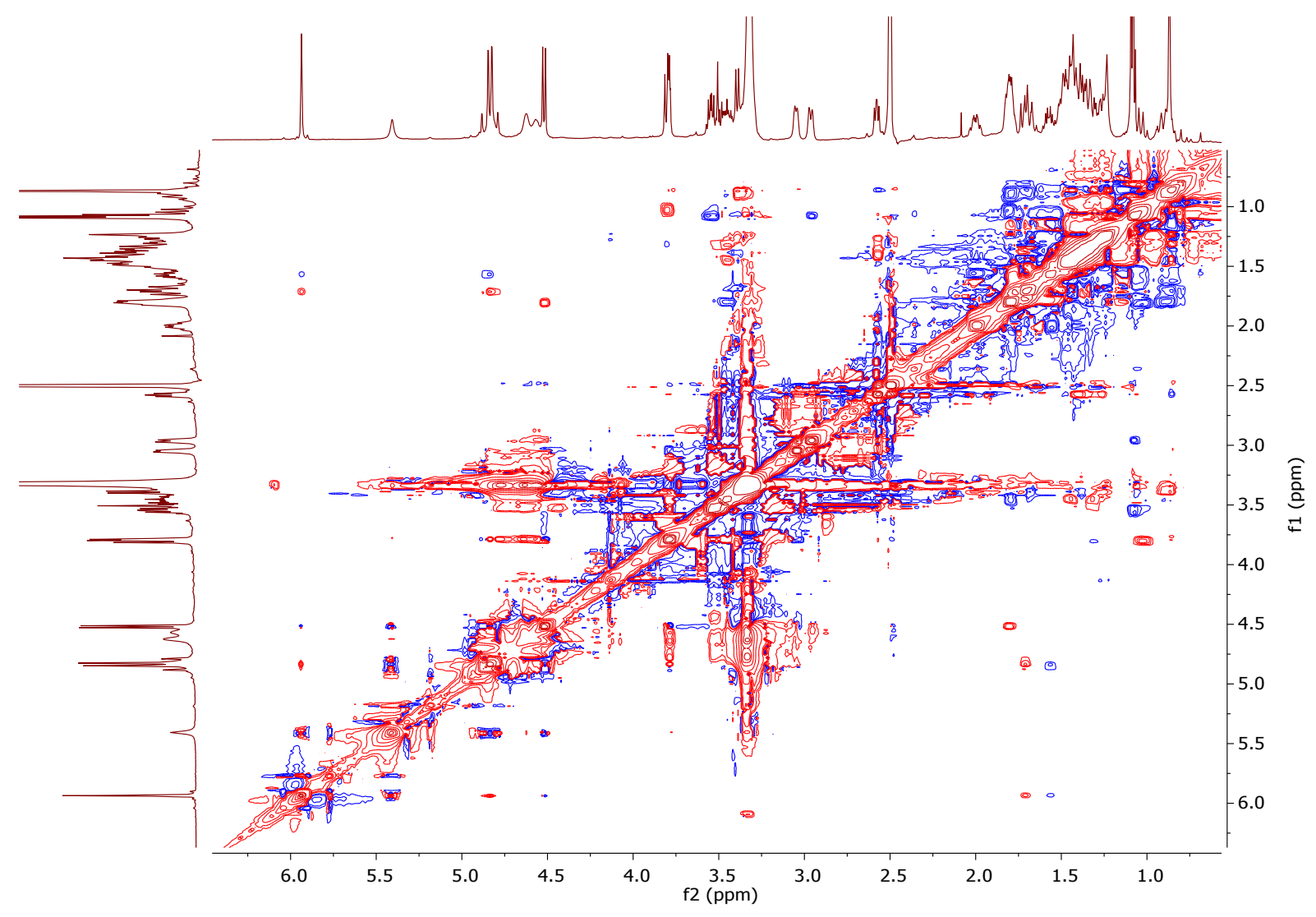

Figure S23. NOESY NMR spectrum of compound 4 


\section{Display Report}
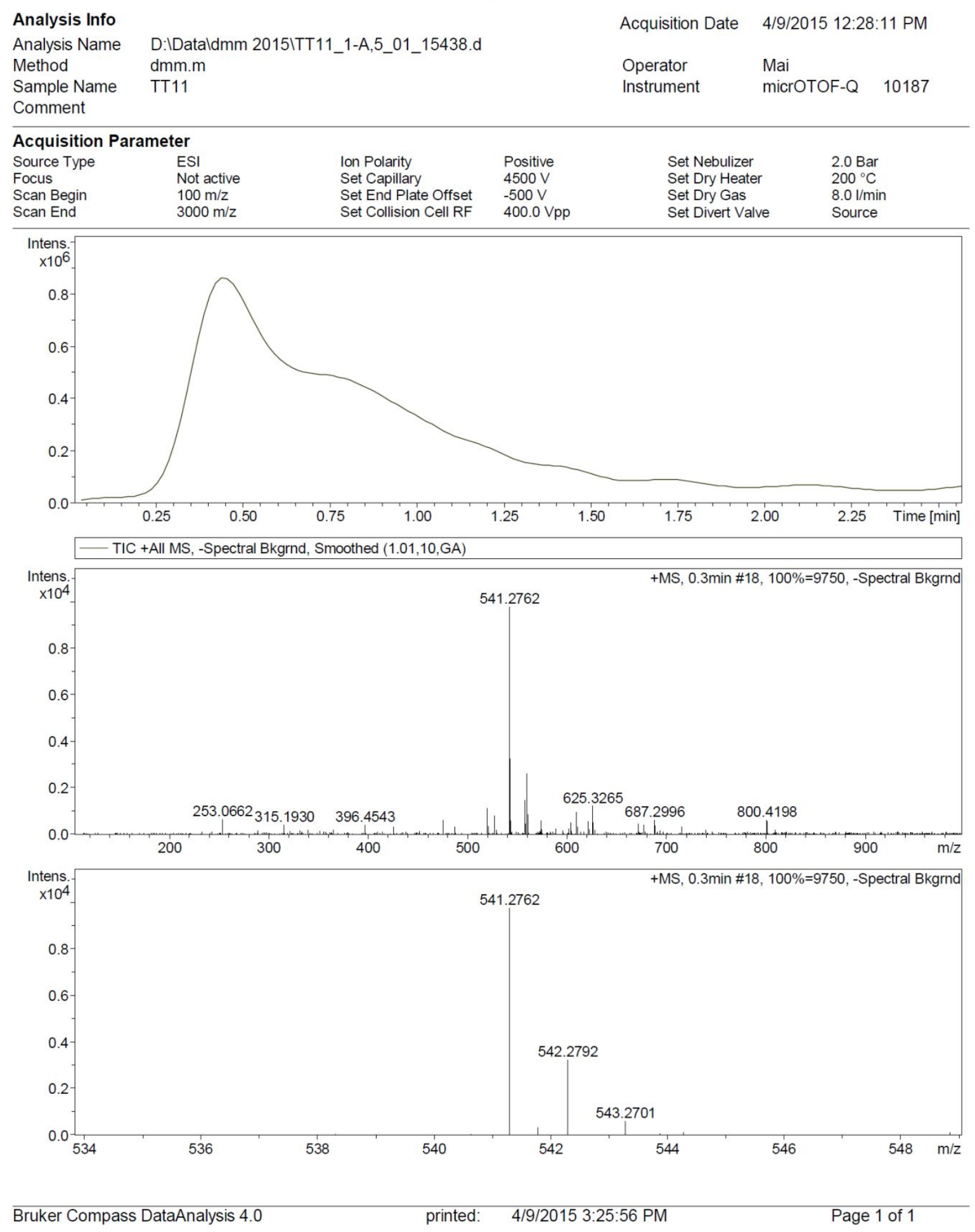

Figure S24. HR-ESIMS of compound 4 


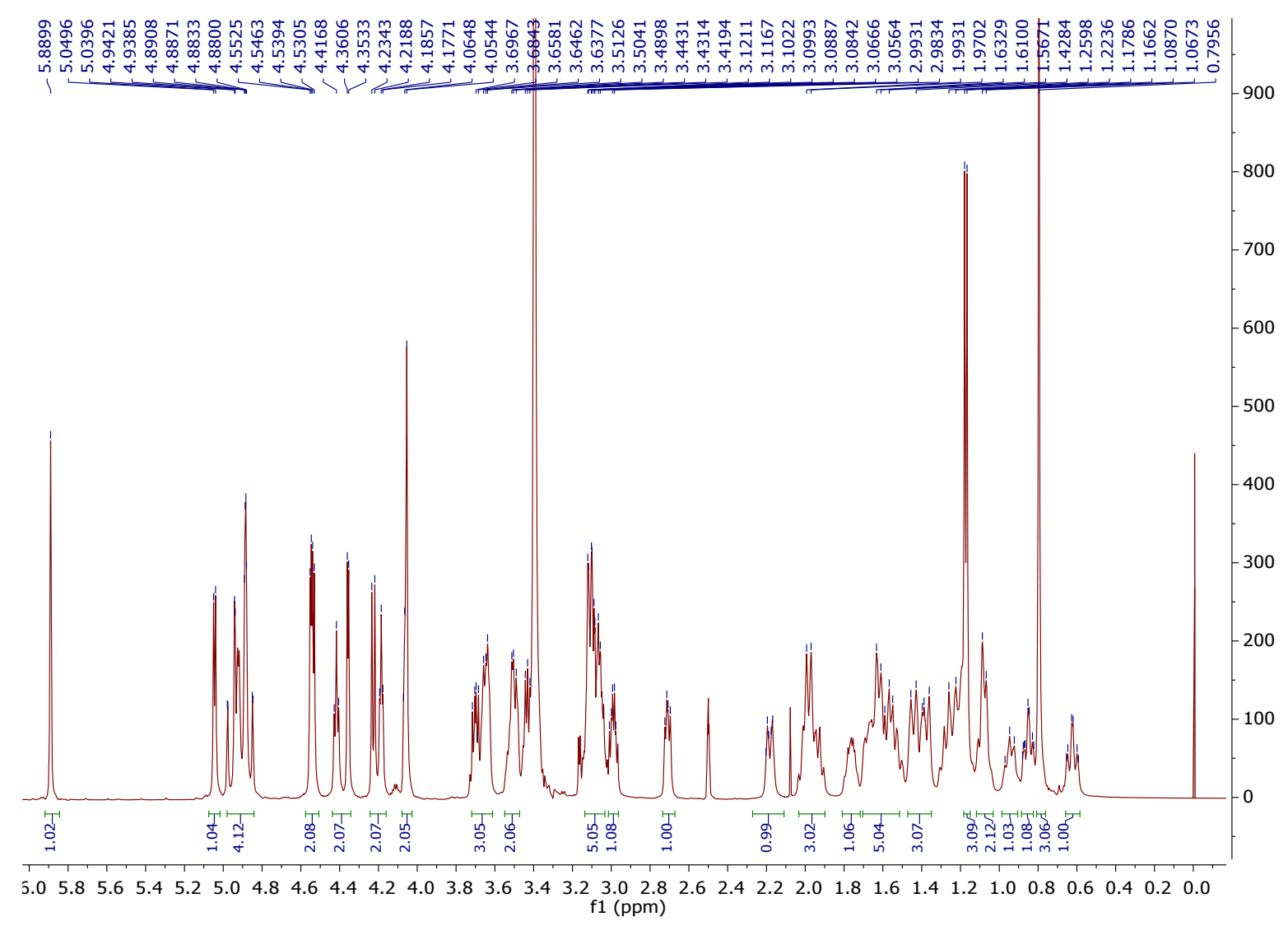

Figure S25. ${ }^{1} \mathrm{H}$ NMR spectrum of compound $5\left(500 \mathrm{MHz}\right.$, DMSO- $\left.d_{6}\right)$

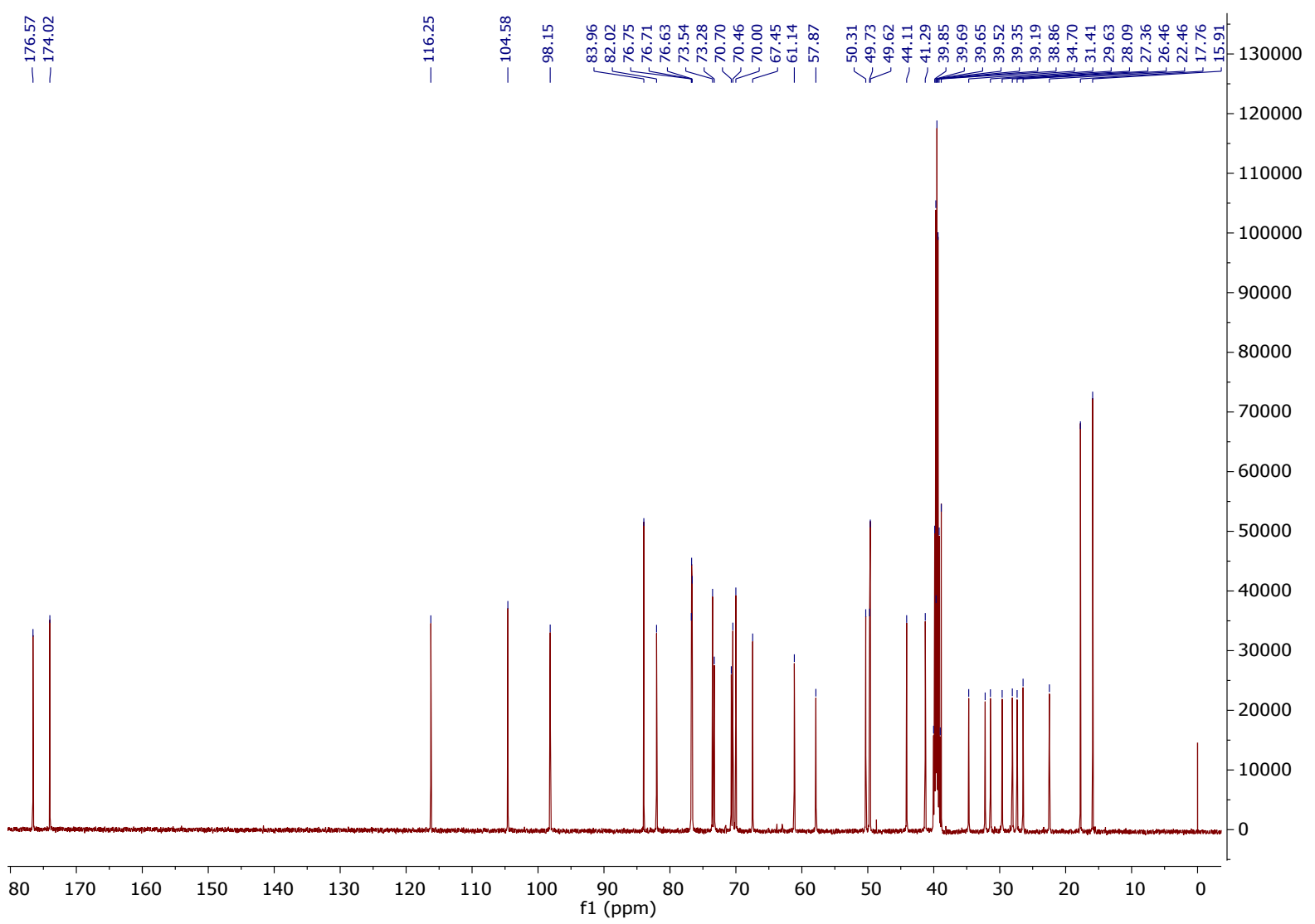

Figure S26. ${ }^{13} \mathrm{C}$ NMR spectrum of compound $5\left(125 \mathrm{MHz}\right.$, DMSO- $\left.d_{6}\right)$ 


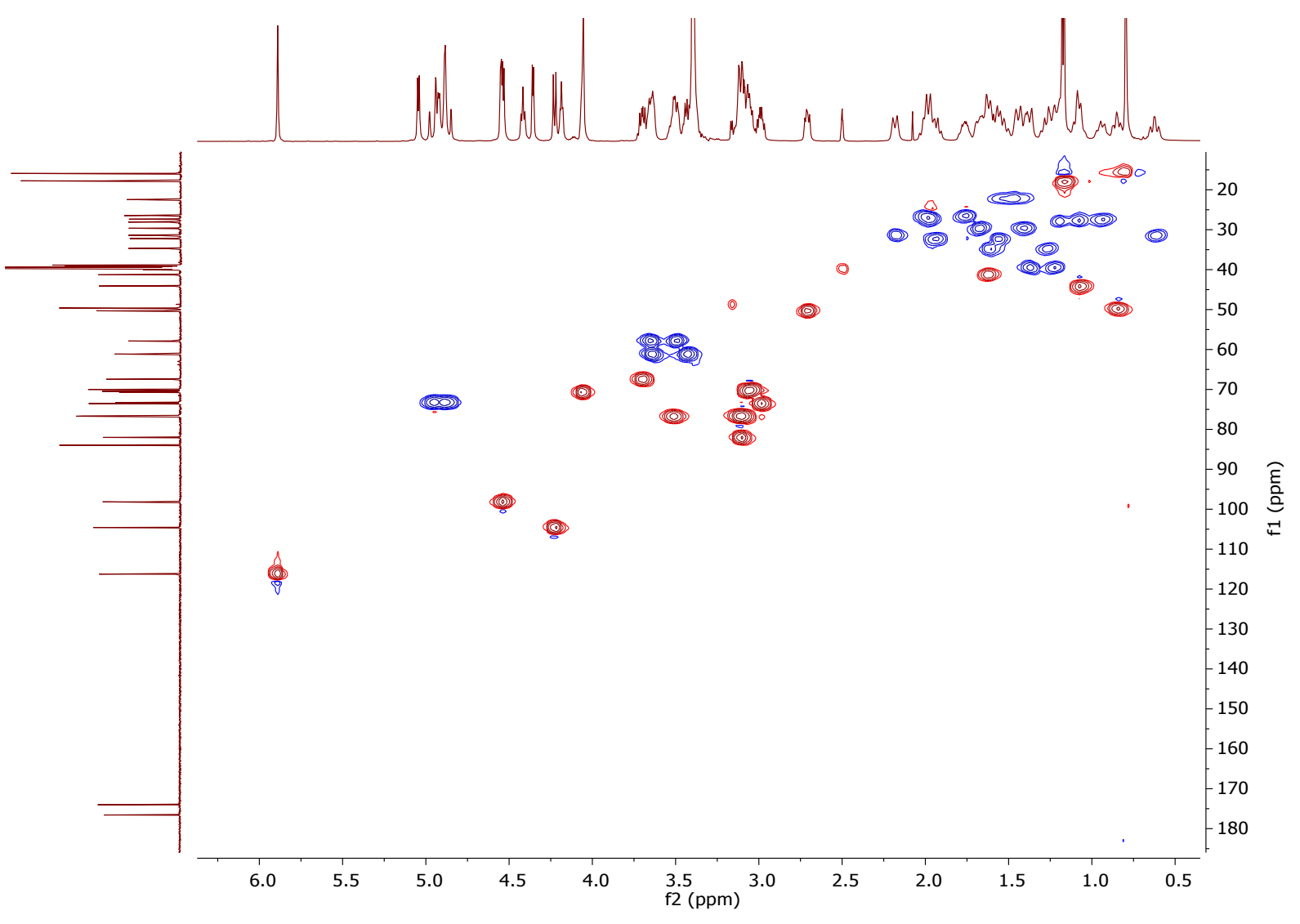

Figure S27. HSQC NMR spectrum of compound $\mathbf{5}$

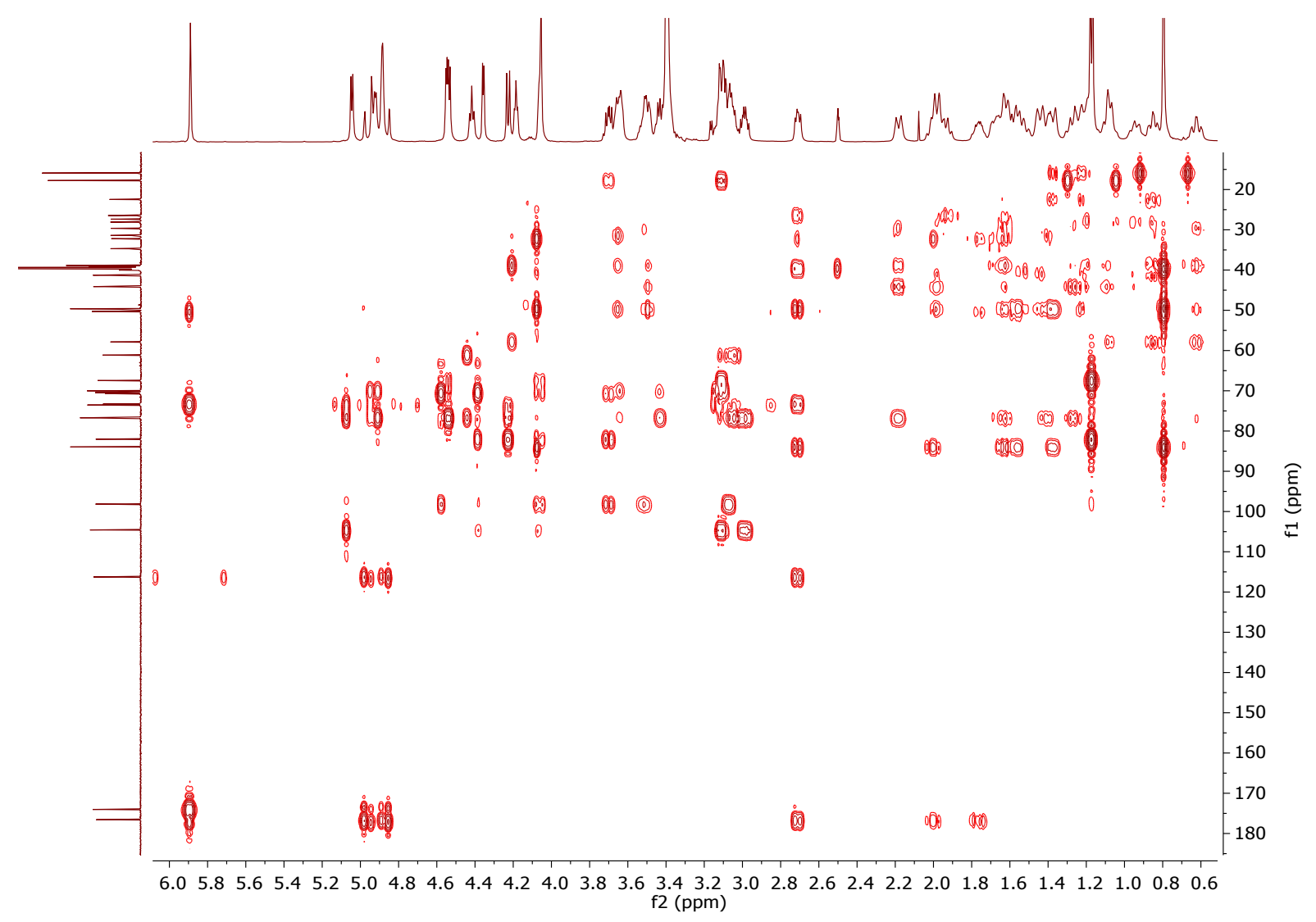

Figure S28. HMBC NMR spectrum of compound 5 


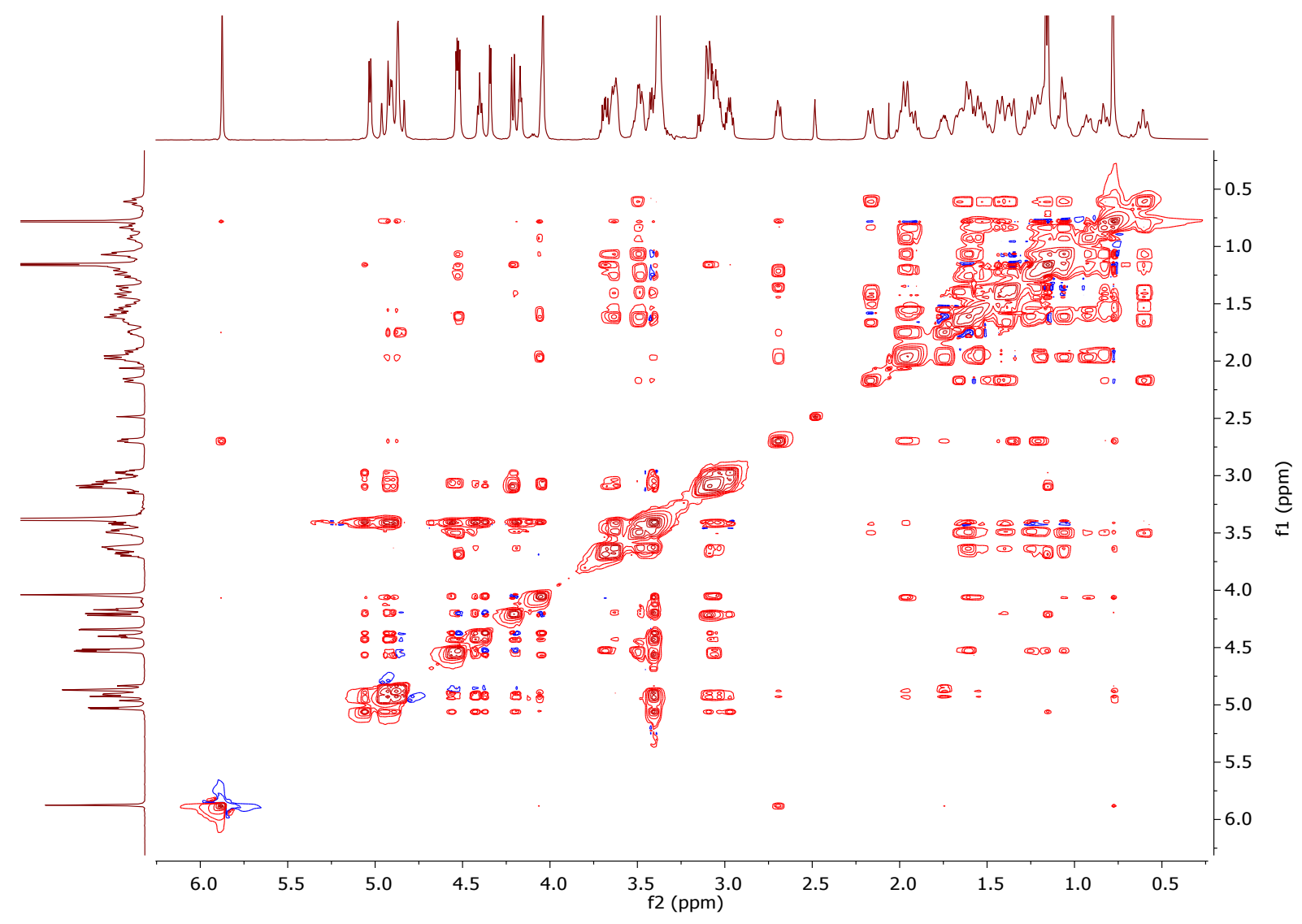

Figure S29. NOESY NMR spectrum of compound $\mathbf{5}$ 


\section{Display Report}

Analysis Info

Analysis Name

Method

Sample Name

Comment

\section{Acquisition Parameter}

Source Type

Focus

Scan Begin

Scan End

D:IDataldmm 2015IDK 64_1-D,5_01_16188.d

dmm.m

DK 64

ESI

Not active

$100 \mathrm{~m} / \mathrm{z}$

$3000 \mathrm{~m} / \mathrm{z}$

Set Capillary

Set End Plate Offse

Set Collision Cell RF

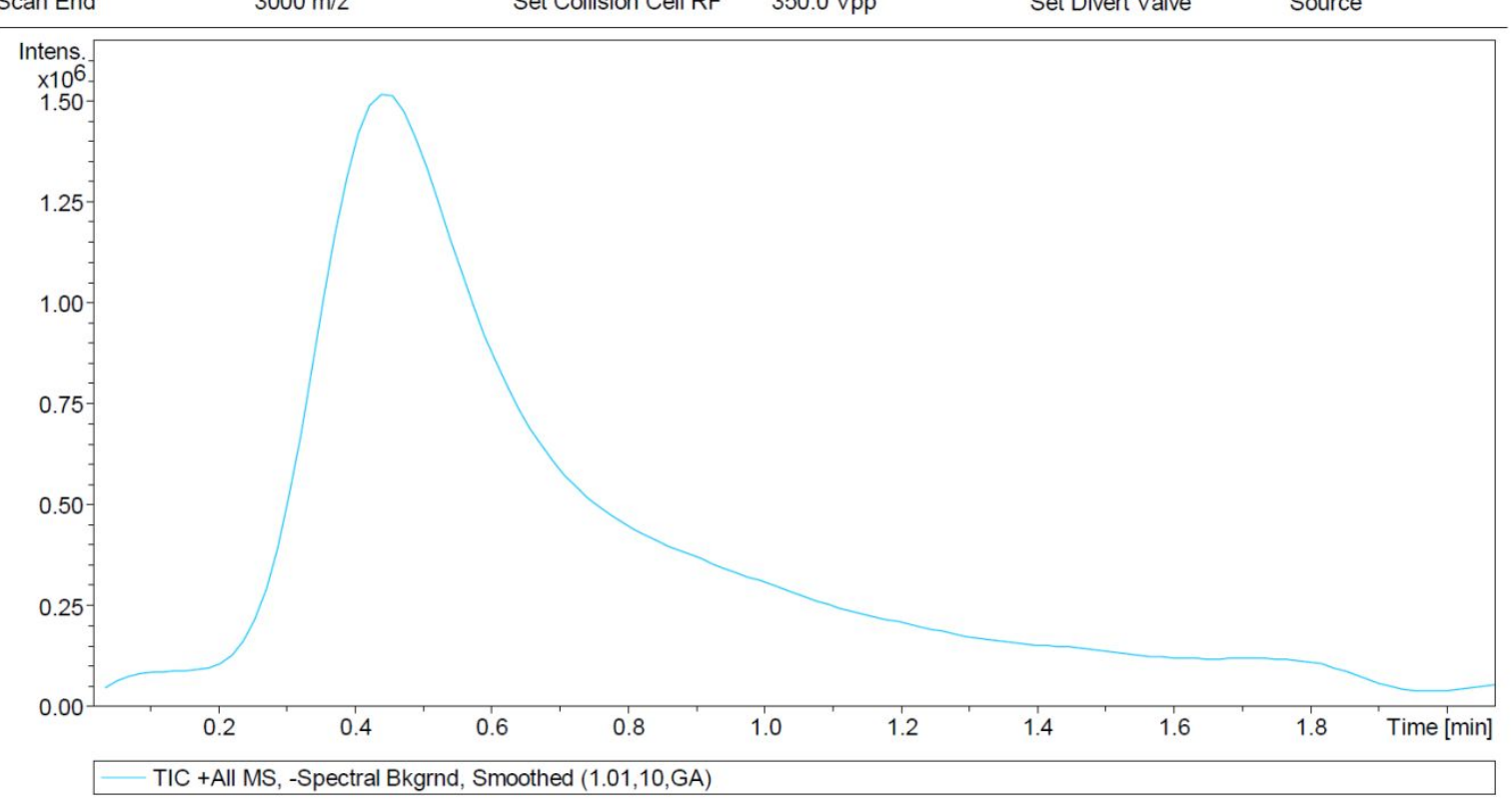

TIC +All MS, -Spectral Bkgrnd, Smoothed $(1.01,10, G A)$

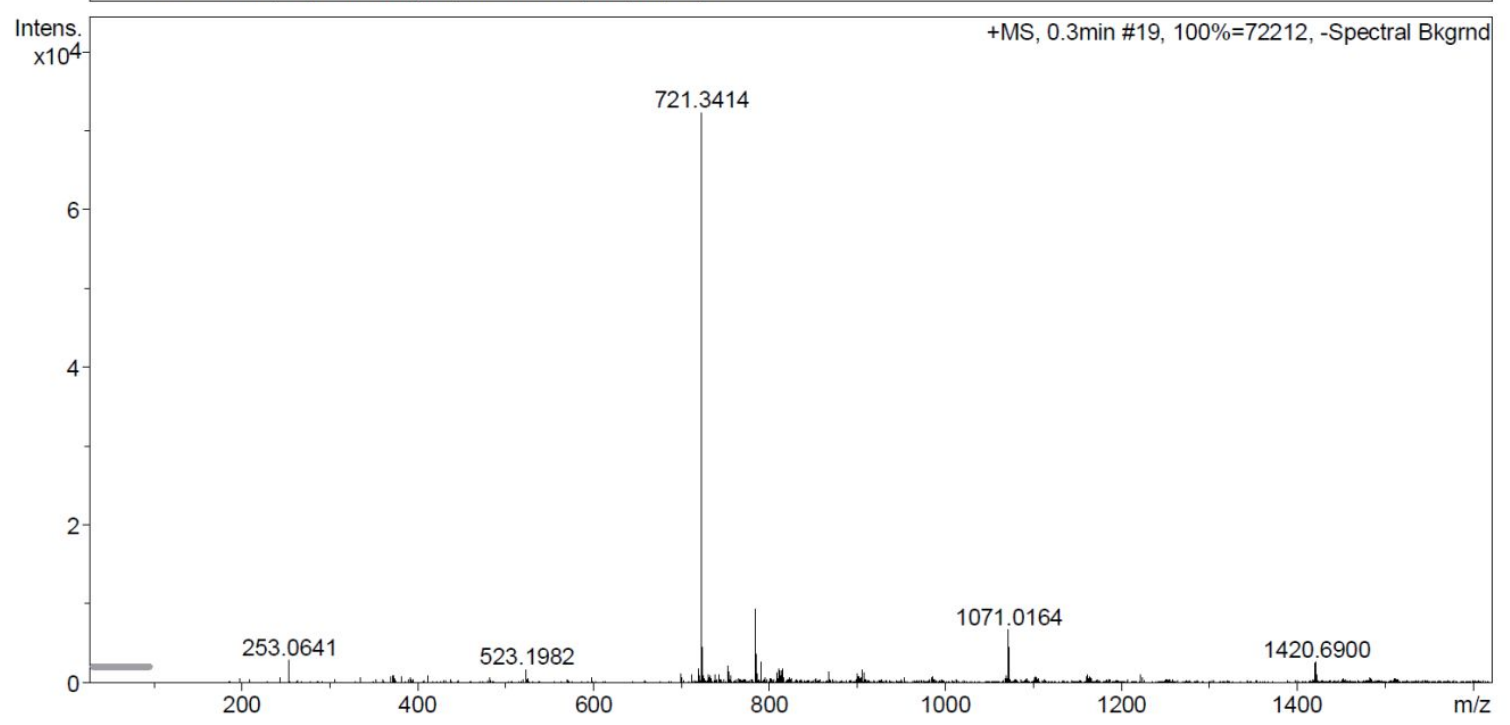

Bruker Compass DataAnalysis 4.0
Acquisition Date 5/25/2015 9:53:36 PM

Operator Mai

Instrument micrOTOF-Q 10187 


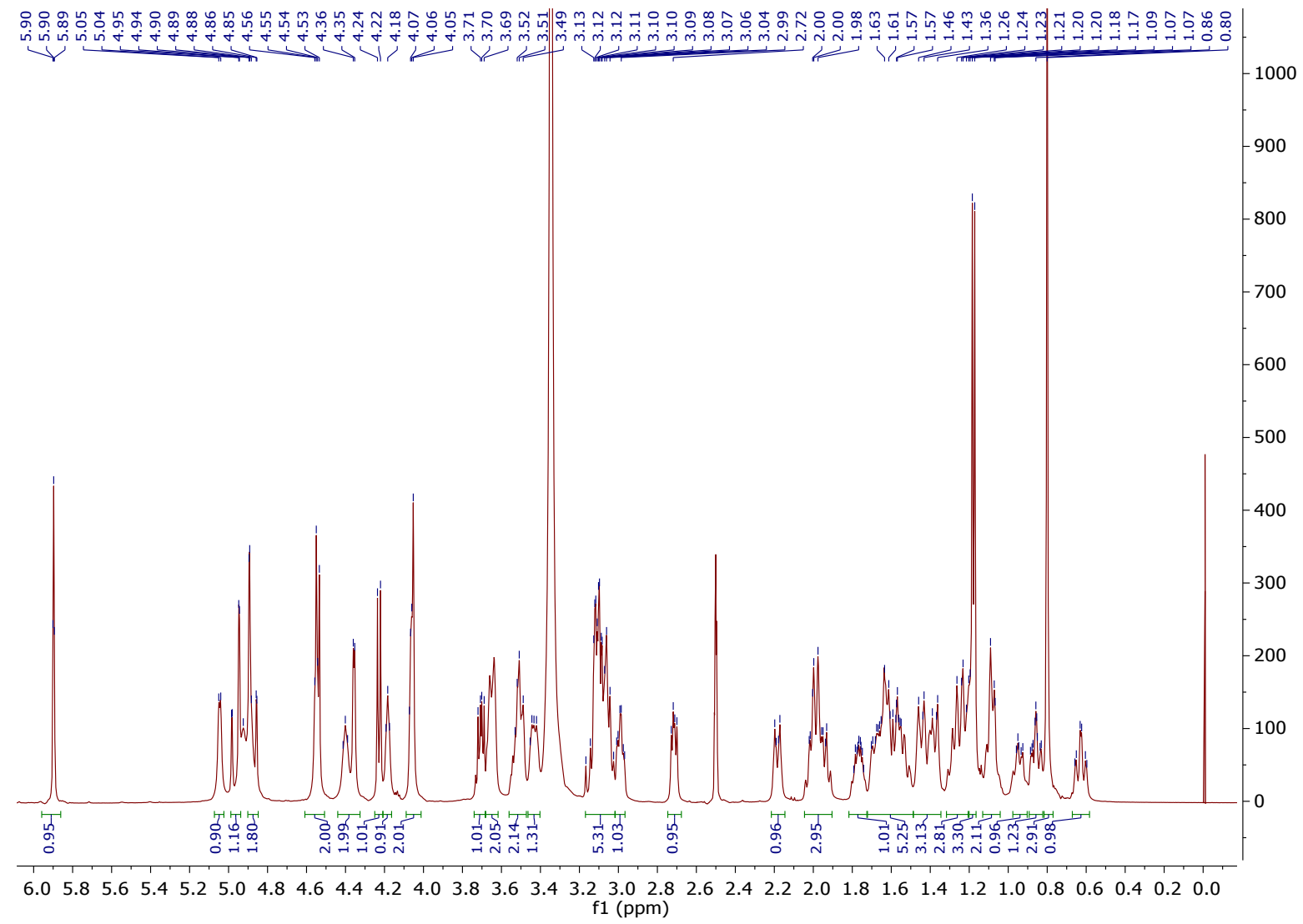

Figure S31. ${ }^{1} \mathrm{H}$ NMR spectrum of compound $6\left(500 \mathrm{MHz}, \mathrm{DMSO}-d_{6}\right)$

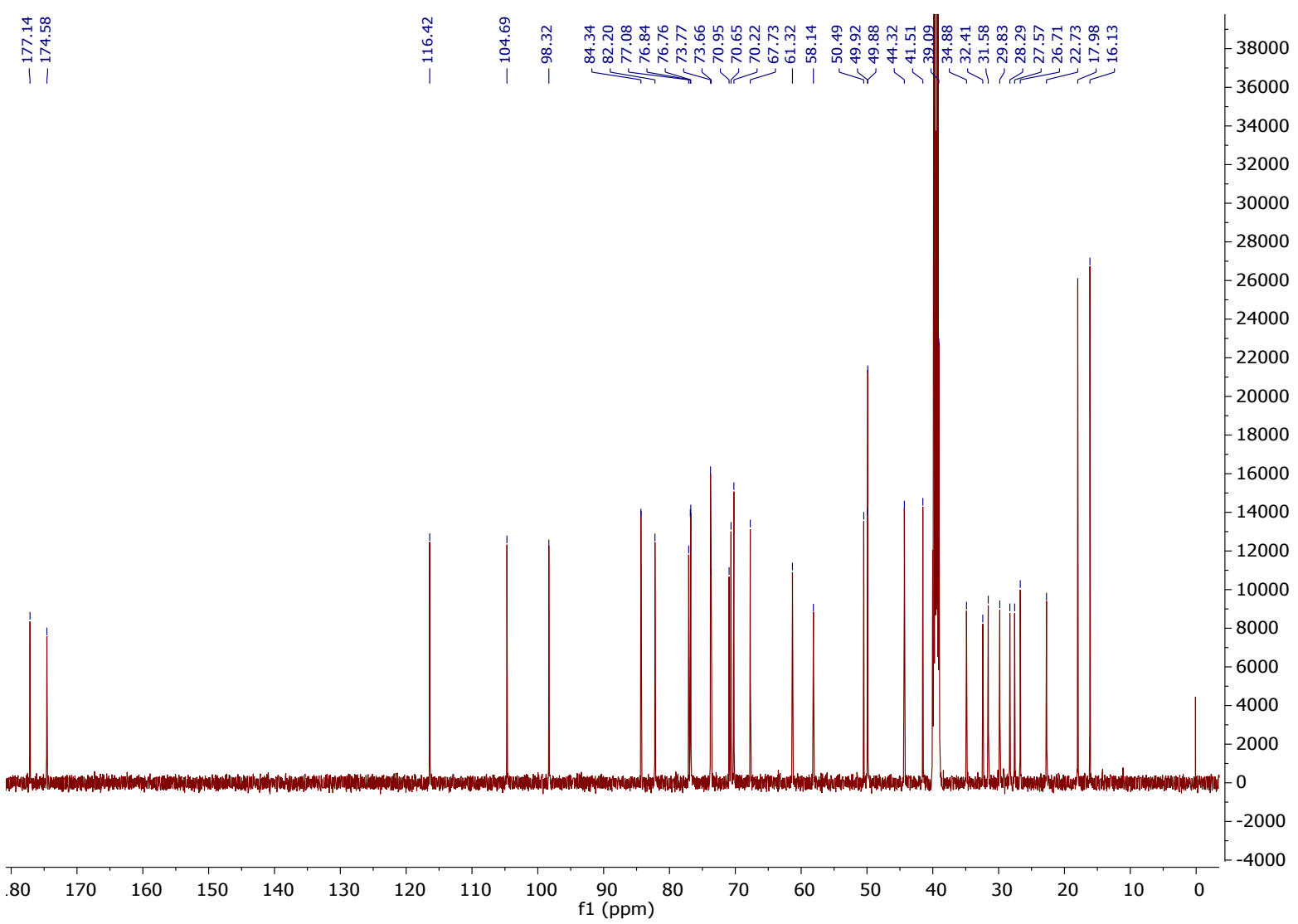

Figure S32. ${ }^{13} \mathrm{C}$ NMR spectrum of compound 6 (125 MHz, DMSO- $\left.d_{6}\right)$ 


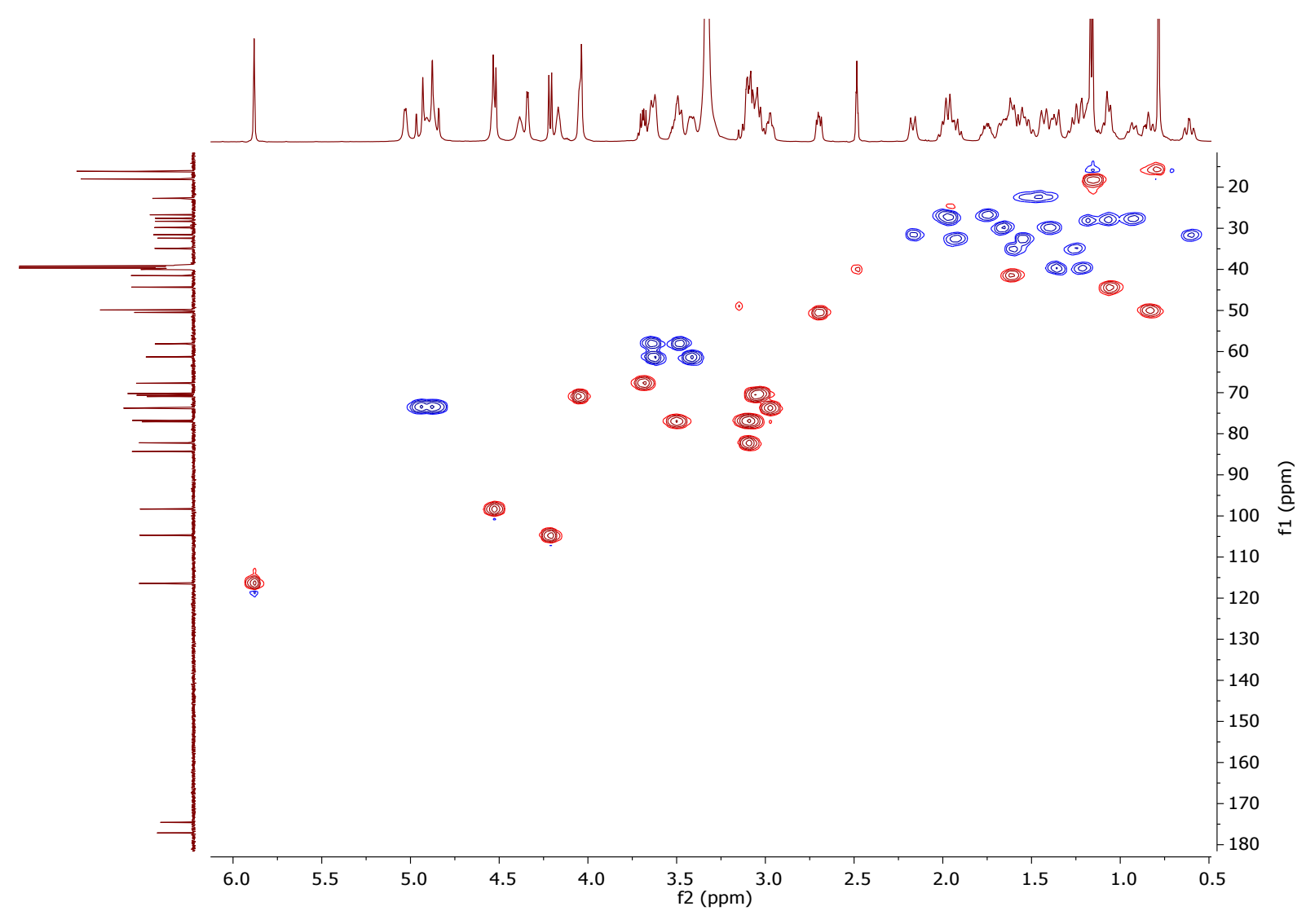

Figure S33. HSQC NMR spectrum of compound 6

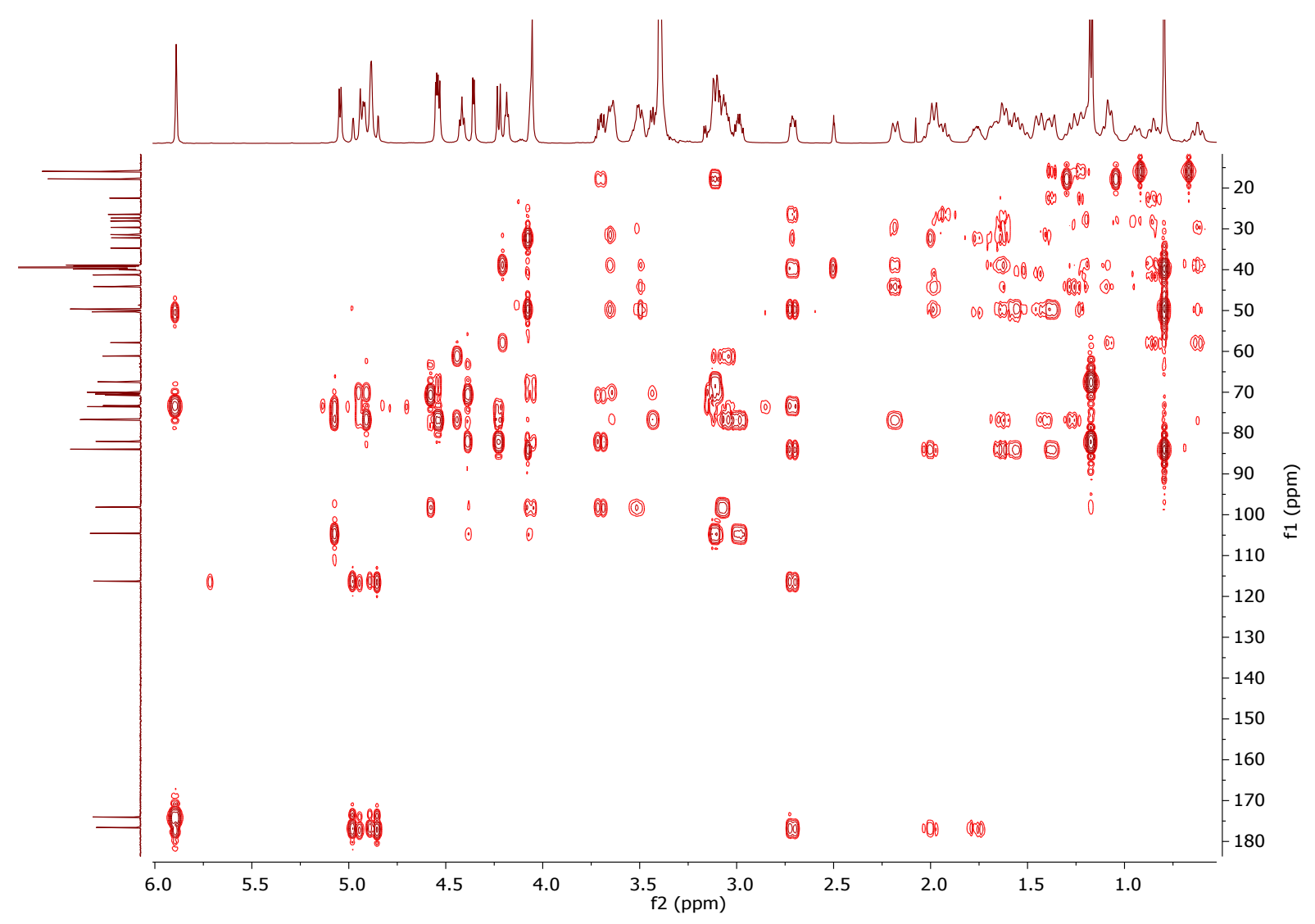

Figure S34. HMBC NMR spectrum of compound 6 


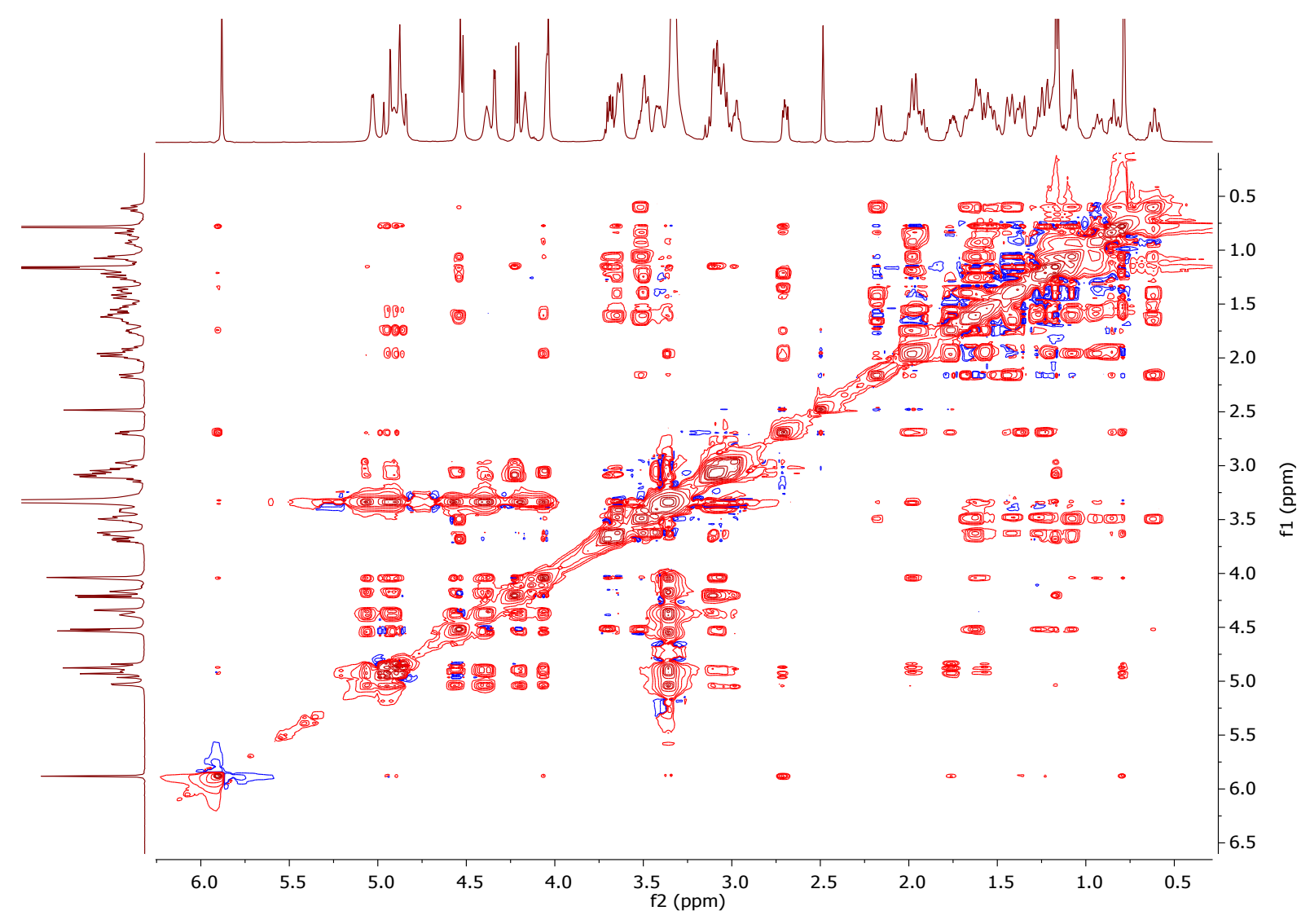

Figure S35. NOESY NMR spectrum of compound 6 


\section{Display Report}

Analysis Info

Analysis Name

Method

Sample Name

Comment
Acquisition Date $\quad$ 5/25/2015 9:23:16 PM

D:IDataldmm 2015IDK 66_1-D,5_01_16188.d

dmm.m

DK 66

Operator Mai

Instrument micrOTOF-Q 10187

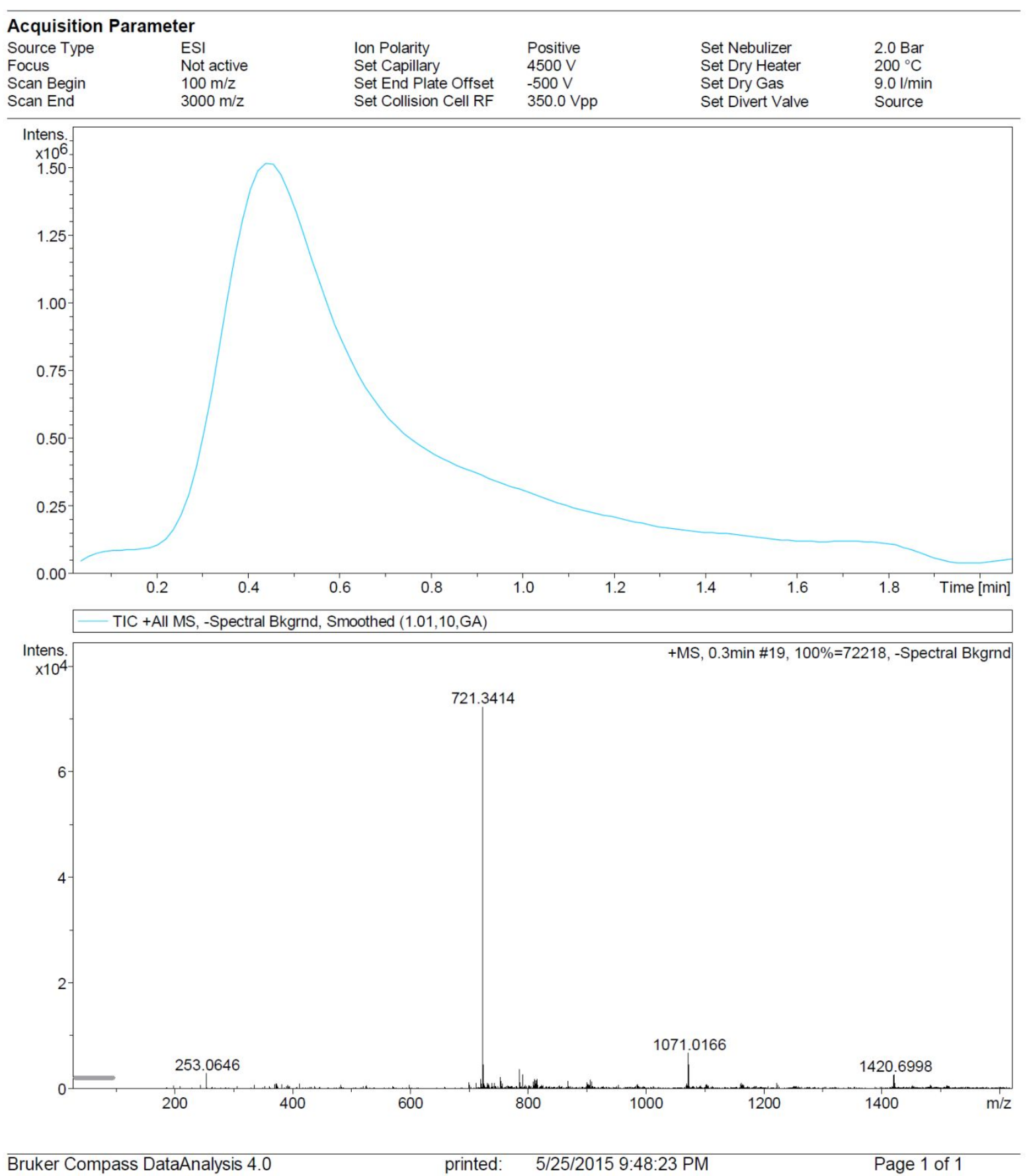

Figure S36. HR-ESIMS of compound 6 